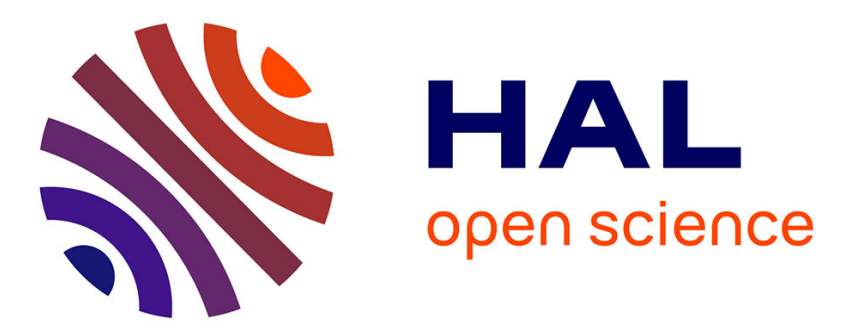

\title{
Effect of aluminizing and oxidation on the thermal fatigue damage of hot work tool steels for high pressure die casting applications
}

Mehdi Salem, Sabine Le Roux, Gilles Dour, Pascal Lamesle, Karim Choquet, Farhad Rezai-Aria

\section{To cite this version:}

Mehdi Salem, Sabine Le Roux, Gilles Dour, Pascal Lamesle, Karim Choquet, et al.. Effect of aluminizing and oxidation on the thermal fatigue damage of hot work tool steels for high pressure die casting applications. International Journal of Fatigue, 2019, 119, pp.126-138. 10.1016/j.ijfatigue.2018.09.018 . hal-01898697

\section{HAL Id: hal-01898697 https://imt-mines-albi.hal.science/hal-01898697}

Submitted on 15 Feb 2019

HAL is a multi-disciplinary open access archive for the deposit and dissemination of scientific research documents, whether they are published or not. The documents may come from teaching and research institutions in France or abroad, or from public or private research centers.
L'archive ouverte pluridisciplinaire HAL, est destinée au dépôt et à la diffusion de documents scientifiques de niveau recherche, publiés ou non, émanant des établissements d'enseignement et de recherche français ou étrangers, des laboratoires publics ou privés. 


\title{
Effect of aluminizing and oxidation on the thermal fatigue damage of hot work tool steels for high pressure die casting applications
}

\author{
M. Salem*, S. Le Roux, G. Dour ${ }^{1}$, P. Lamesle ${ }^{2}$, K. Choquet, F. Rézaï-Aria \\ Université de Toulouse, CNRS, Mines Albi, INSA, UPS, ISAE-SUPAERO, ICA (Institut Clément Ader), Campus Jarlard, F-81013 Albi, France
}

A B S T R A C T

The interaction between thermal fatigue and aluminizing and/or oxidation is investigated using an experimental approach based on decoupling of mechanisms. Virgin and pre-aluminized steel specimens are tested in air and nitrogen between 100 and $650^{\circ} \mathrm{C}$. Homogeneous uniaxial micro-crack network forms on the oxidised or prealuminized surface in air, with a better resistance to micro-cracking for the intermetallic coating. The propagation of the micro-cracks is delayed in nitrogen, whilst no evidence of micro-cracking is observed on the virgin specimen. The premature cracking of the steel depends on the formation of the superficial micro-crack network, and the crack propagation is assisted by oxidation.

\section{Keywords:}

Thermal fatigue

Intermetallics

Corrosion

Cracks

Tool steel

\section{Introduction}

In the High Pressure Die Casting (HPDC) process, molten aluminium is injected between 650 and $700{ }^{\circ} \mathrm{C}$ in the cavities of the mould, at a speed higher than $30 \mathrm{~m} / \mathrm{s}$ and under high pressure (up to $1300 \mathrm{bar}$ ) [1]. The surface of the mould is thus exposed to strong thermo-mechanical loadings and severe corrosive attacks. It is damaged by complex mechanisms combining thermal fatigue (TF), wear (by shock or friction) and corrosion (by aluminizing and oxidation) [2,3], which impact the industrial process in different ways [4].

After several thousand cycles, the mould cavities (especially the gate areas) may suffer a substantial and irreversible loss of material called "washout" -, which decreases their ability to meet the dimensional tolerance of cast parts $[5,6]$. This phenomenon is attributed to the interaction between erosion and corrosion, which leads eventually to the dissolution of the die [6-8]. In service, the surface of the die keeps its initial quality as long as it remains protected against oxidation or aluminizing by the lubricant coating [8,9], as shown in Fig. 1a. By stripping the die surface in areas of high flow (e.g. gate) or with direct impingement (e.g. pins in front of the gate), erosion enables the molten aluminium to come into contact with the surface of the steel mould. The inter-diffusion of aluminium and iron atoms results in the formation of intermetallic compounds at the interface between cast alloy and steel $[9,10]$. Post-mortem metallographic analyses of industrial dies $[9,11,12]$ have indeed highlighted the presence of oxide (Fig. 1b) and/ or intermetallic phases (Fig. 1c), both in surface and inside cracks. Oxide and intermetallic compounds contribute to modify the chemical composition of the steel sub-surface, and consequently its mechanical behaviour [13]. Among the phases composing the complex aluminide layer, the $\mathrm{Fe}_{2} \mathrm{Al}_{5}(\mathrm{Si})$ phase formed just above the mould surface is particularly compact and brittle. In addition, sticking problems - also known as "soldering" - manifests by a total or partial attachment of the cast part on the die. This adhesion may be caused by chemical interaction between aluminium and iron $[7,8,14-16]$ or by mechanical bonding, due to the infiltration of the aluminium through the cracks from the "heat-checking" which is the main damage mode experienced by mould cavities after a large number of cycles $[12,17,18]$. The soldering issues require stopping the production to remove the part manually and rectifying the tool surface by mechanical processes (machining, grinding, etc.) $[6,8]$. In service, the die surface undergoes strong alternate heating-cooling cycles, respectively in the injection phase and the opening step during which the part is ejected and a lubricant is sprayed onto the mould surface. As a result of these high transient thermal gradients, thermal stresses are induced at the surface of the mould cavity where cracks are initiated by anisothermal low cycle fatigue process. The micro-cracks grow to form a superficial network, either multi-axial on plane surfaces (Fig. 1d) or uniaxial in geometrical singularities (Fig. 1e) [19]. The formation of a macroscopic heat-checking network on the mould significantly reduces the quality of produced parts, requiring subsequent finishing operations and the

\footnotetext{
* Corresponding author.

E-mail address: mehdi.salem@mines-albi.fr (M. Salem).

${ }^{1}$ Present address: Advisian, Worley Parsons, Perth, Australia.

${ }^{2}$ Present address: IRT-M2P, Bâtiment CIRAM, 4 rue Augustin Fresnel, 57070 Metz, France.
} 

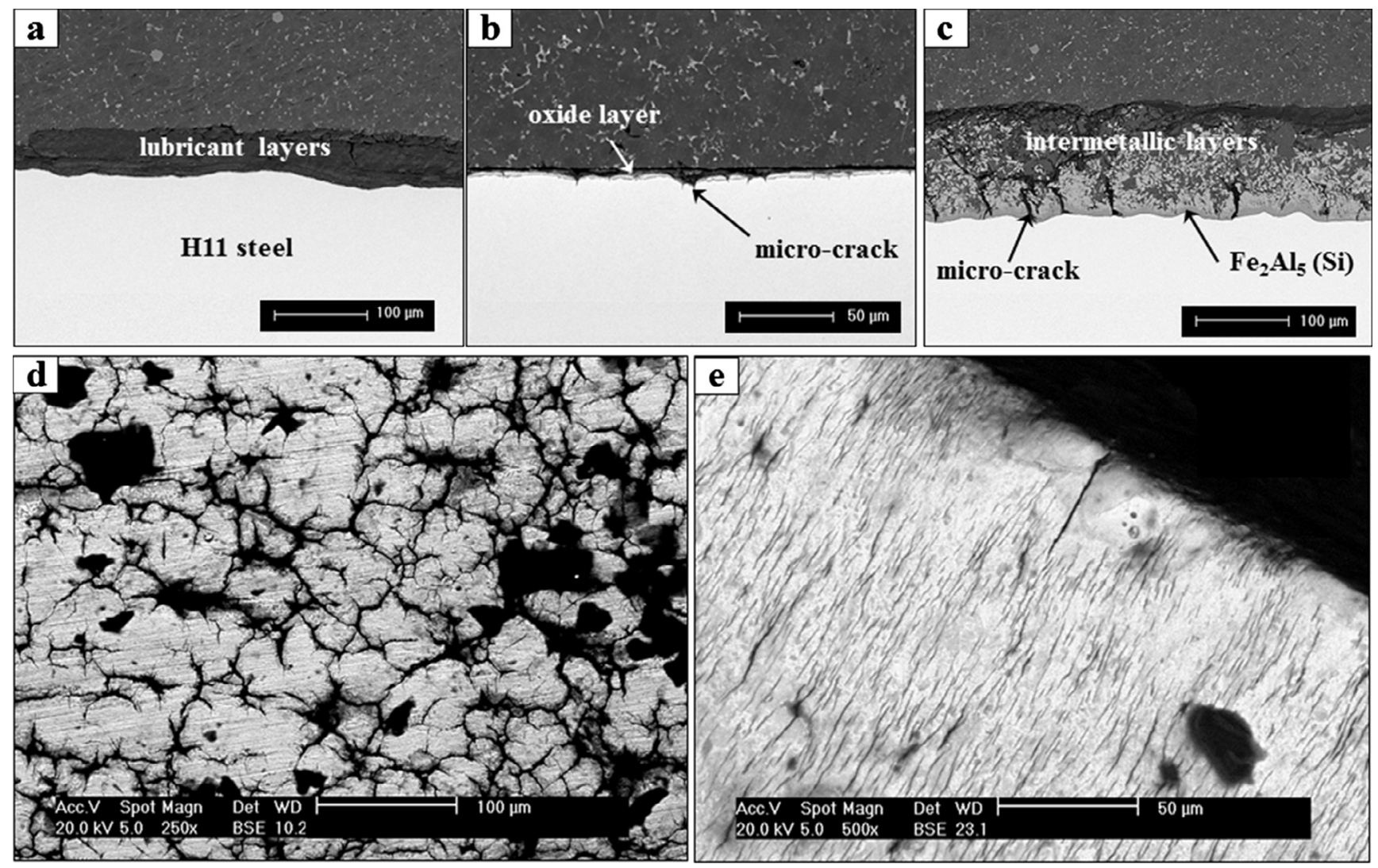

Fig. 1. SEM observations on X38CrMoV5 (AISI H11) pin of AlSi9Cu3 high pressure die casting mould: undamaged (a), oxidized (b) and aluminising (c) areas in cross section; multi-axial (d) and uniaxial (e) "heat-checking" network in surface [9].

scrapping of the die when the defects are too large. Moreover, macrocracks can propagate in-depth in the tool, leading to its premature retirement if not rupture $[4,20,21]$.

Understanding the interactions between the different damage mechanisms involved in HPDC is therefore essential for the casting industry, in order to optimize the service conditions and to better design the material solutions to extend the tool life. The effect of the environment, especially oxidation, is well known in low cycle fatigue (LCF) [22], but not yet clearly identified in TF, despite a large number of reported studies $[3,18,23-28]$. All these works emphasize the impact of the oxidation or/and aluminizing on TF damage of tool steels. But unlike isothermal fatigue tests, the TF test is still not standardized and the applied solicitations vary depending on the heating and cooling devices and the specimen geometry chosen by each author. This diversity of test conditions complicates the comparison of the different TF results in order to quantify the environment effects objectively.

This contribution is an attempt to better understand the influence of the corrosive environment - both oxidation and aluminizing - on the TF behaviour of a hot work tool steel X38CrMoV5 (AISI H11). The role of the $\mathrm{Fe}-\mathrm{Al}$ intermetallic compounds, resulting from the steel aluminizing, is investigated based on TF experiments performed on coated specimens. Several techniques can be used to prepare an aluminium coating, such as Physical Vapour Deposition (PVD), Chemical Vapour Deposition (CVD), Hot-Dipping (HD), Electro-Chemical Deposition (ECD), Plasma Sputtering (PS), cladding, spraying, etc. [29-31]. In our case, a low-temperature process allowing the formation of a homogeneous layer on a complex geometry was required, in order to avoid microstructural changes of the heat-treated steel, which would result in the degradation of its mechanical properties by thermal softening [32]. Among processes meeting these constraints, the low-temperature CVD process using Pack Cementation (PC) was selected for its simplicity of use and because it allows a fine surface finish [9]. To investigate the role of oxidation, TF fatigue experiments are performed in air and nitrogen, and compared to the same tests on uncoated specimens (virgin steel). The superficial damage and microstructural evolutions are analysed using Scanning Electron Microscopy (SEM) and X-Ray Diffraction (XRD). The effects of the intermetallic and oxide layers on crack initiation and lifetime of the steel are presented and discussed.

\section{Experimental procedure}

\subsection{Material and specimens}

A low silicon and impurity grade of X38CrMoV5 tool steel (AISI H11), known as ADC3 and provided by Aubert \& Duval, was investigated. Its chemical composition is given in Table 1 . The steel was heat-treated by austenitisation at $980^{\circ} \mathrm{C}$ for $1 \mathrm{~h}$, then quenching in air, and double tempering at 550 and $605^{\circ} \mathrm{C}$ for $2 \mathrm{~h}$ at each temperature, resulting in a martensitic microstructure with a final hardness of about 47 HRC [9].

Disk shaped axi-symmetric specimens with an outer diameter of $30 \mathrm{~mm}$ and $1 \mathrm{~mm}$ thickness were machined from the heat-treated bars. An axial hole of $10 \mathrm{~mm}$ diameter was drilled in the specimen for internal water-cooling (Fig. 2). The surface of the specimen at tips was polished along the circumferential direction $(\theta \theta)$ to achieve a mean roughness $R a$ of about $0.05 \mu \mathrm{m}$.

Table 1

Chemical composition of the X38CrMoV5 (AISI H11) tool steel.

\begin{tabular}{llllllllll}
\hline Element & $\mathrm{C}$ & $\mathrm{Cr}$ & $\mathrm{Mo}$ & $\mathrm{V}$ & $\mathrm{Si}$ & $\mathrm{Mn}$ & $\mathrm{S}$ & $\mathrm{P}$ & $\mathrm{Fe}$ \\
\hline Weight\% & 0.36 & 5.06 & 1.25 & 0.49 & 0.35 & 0.36 & 0.0011 & 0.006 & bal.
\end{tabular}




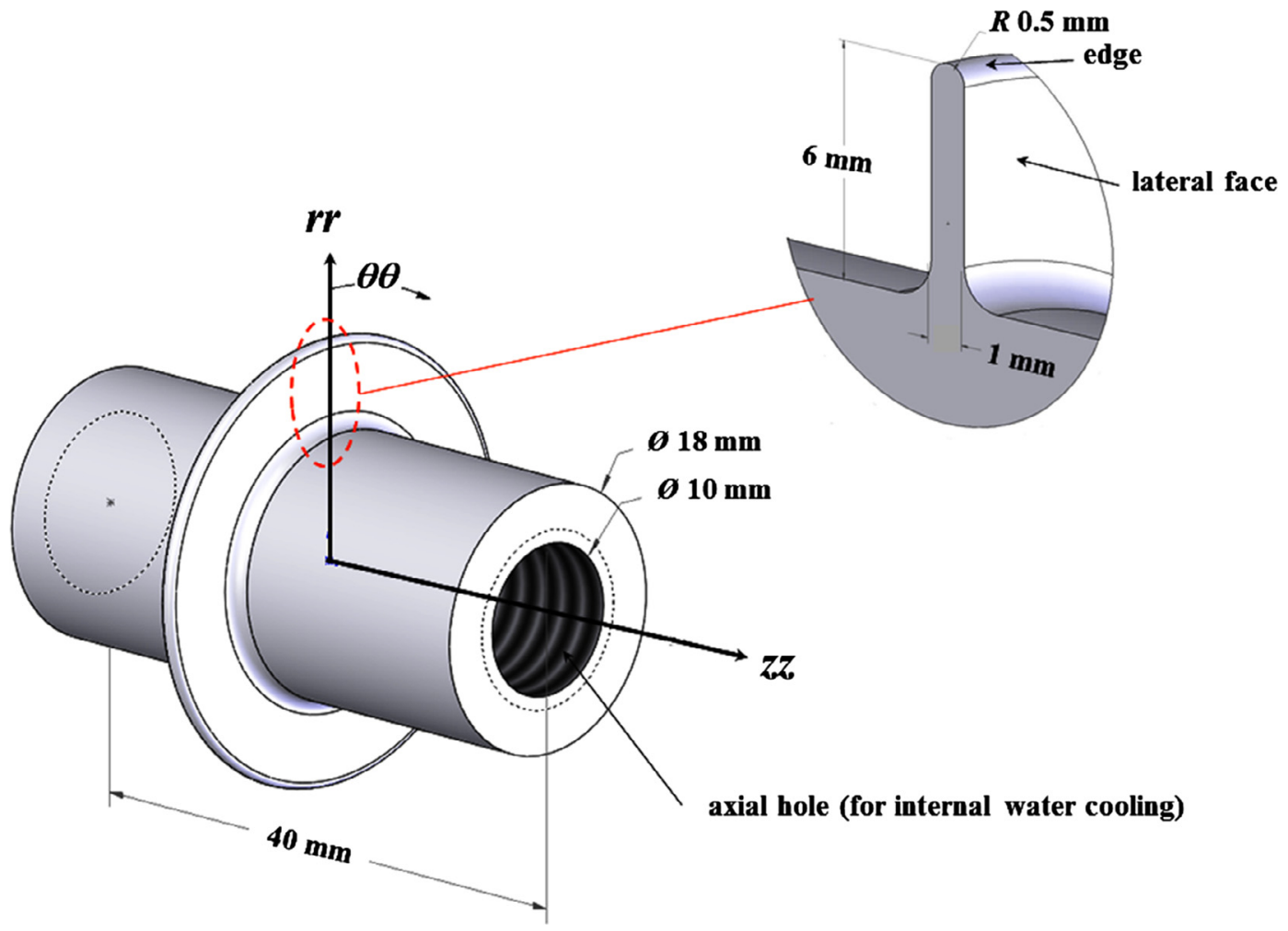

Fig. 2. Geometry and dimensions of the thermal fatigue specimens.

\subsection{Thermal fatigue experiments}

A new TF rig, equipped with a vacuum chamber with an Al-double water-cooled wall, was developed in order to perform TF experiments in ambient laboratory air or inert atmosphere (nitrogen $\mathrm{N}_{2}$ or argon Ar). The heating facility consisted of a $25 \mathrm{~kW}$-Hüttinger high frequency induction generator, coupled with a solenoid inductor coil placed inside the chamber (Fig. 3a). The induction frequency was about $2-4 \mathrm{MHz}$, resulting in a rapid heating of the outer radius (tip) of the specimen. The depth of the induction "skin effect" was estimated to be a few tens of micrometres. The specimen was carefully positioned inside the induction coil using a movable sample holder (Fig. 3b). A temperature variation less than $5^{\circ} \mathrm{C}$ (at $650^{\circ} \mathrm{C}$ ) was achieved along the circumferential direction. The inner wall of the specimen was continuously cooled by water at $20^{\circ} \mathrm{C}$, with a flow rate of about $10 \mathrm{l} / \mathrm{min}$. The external surface of the specimen was naturally cooled by convection and radiative losses. Severe thermal gradients were induced inwardly from the specimen tip. The temperature was measured by a K-type thermocouple with a wire diameter of $80 \mu \mathrm{m}$, spot-welded at the tip of the specimen. The variation of temperature versus time was collected with data acquisition system developed in-house, using National Instrument ${ }^{\circledR}$ hardware and Labview ${ }^{\circledast}$ software. For experiments in $\mathrm{N}_{2}$ or $\mathrm{Ar}$, the gas was introduced after a primary $\left(4.10^{-2} \mathrm{mbar}\right)$ and secondary $\left(5.10^{-}\right.$ ${ }^{5} \mathrm{mbar}$ ) vacuum respectively. The oxygen and water vapour contents in the inert gas were very low ( $<3 \mathrm{ppm}$, see Table 2$)$. Several purges were performed before each test. During the test, the chamber was put under slight overpressure (around 1.2 bar) and the gas was stirred using a ventilator [9].

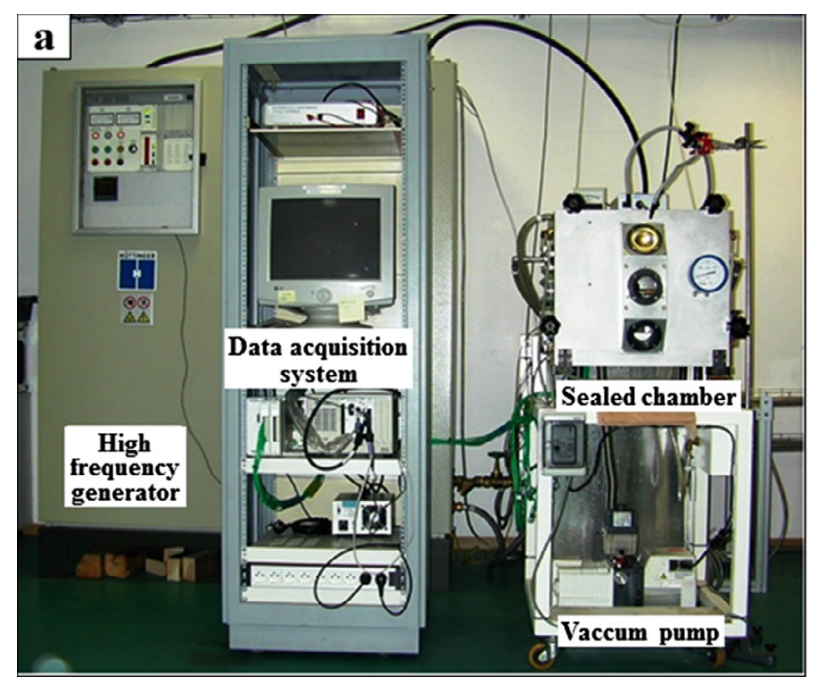

$\mathbf{b}$

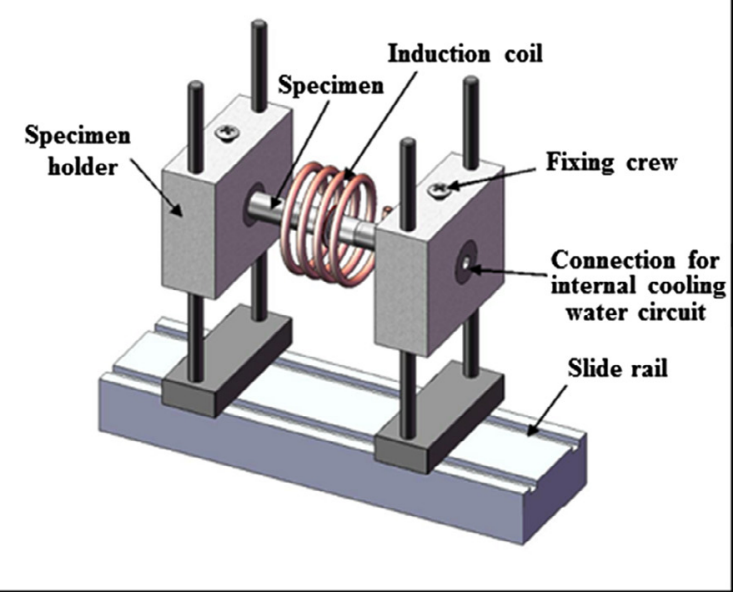

Fig. 3. (a) General view of the thermal fatigue rig, (b) detailed schema of heating and specimen holder devices. 
Table 2

Impurity content in the argon and nitrogen gases used for the TF tests.

\begin{tabular}{llll}
\hline & $\mathrm{H}_{2} \mathrm{O}$ & $\mathrm{O}_{2}$ & $\mathrm{C}_{\mathrm{n}} \mathrm{H}_{\mathrm{n}}$ \\
\hline Argon $(\alpha \mathrm{Ar})$ & $<3 \mathrm{ppm}$ & $<2 \mathrm{ppm}$ & $<0.5 \mathrm{ppm}$ \\
Nitrogen $\left(\alpha \mathrm{N}_{2}\right)$ & $<3 \mathrm{ppm}$ & $<2 \mathrm{ppm}$ & $<0.5 \mathrm{ppm}$ \\
\hline
\end{tabular}

The thermal cycle imposed at the edge of the specimen varied between a minimum temperature $\left(T_{\min }\right)$ of $100{ }^{\circ} \mathrm{C}$ and a maximum temperature $\left(T_{\max }\right)$ of $650^{\circ} \mathrm{C}$. The prescribed $T_{\max }$ was achieved by controlling the power of the induction generator, using a PID regulator (Eurotherm ${ }^{\circledast}$ ). The heating time $(h t)$ was then adjusted to $1.25 \mathrm{~s}$, resulting in a mean heating rate of about $420^{\circ} \mathrm{C} \mathrm{s}^{-1}$. The cooling time $(c t)$ was set to $7.4 \mathrm{~s}$, so as to achieve $T_{\min }$.

\subsection{Microstructural characterisation}

The TF experiments were regularly interrupted to observe the evolution of the surface damage (especially the oxidation and micro-crack initiation) by means of optical microscopy and SEM, in order to establish the evolution of both the distance between the micro-cracks $(d)$ and the crack depth $(a)$ as a function of the number of TF cycles $(N)$. The micro-crack initiation was determined by direct observation of the specimen surface, while the lifetime for crack growth was given by the crack propagation curves $(a=\mathrm{f}(N))$. TF crack lifetime was divided in two stages: an initiation stage that involves the growth of superficial small cracks called "micro-cracks" (with a depth smaller than about $50 \mu \mathrm{m}$ ), and a propagation stage that involves the growth of the steel macro-cracks reaching an "engineering" size (up to $0.5 \mathrm{~mm}$ in depth).

In order to identify the oxide and intermetallic phases, XRD analyses were performed from the outer surface of TF coated specimens before and after TF cycling. A Panalytical X'Pert Pro diffractometer was used,

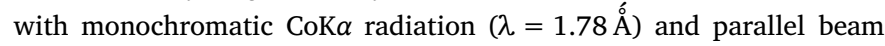
optics (better suited for thin film characterization). The parameters used were an angular step size of $0.01^{\circ}$ an integration time of $5 \mathrm{~s}$, a voltage of $40 \mathrm{kV}$ and a current of $40 \mathrm{~mA}$. In order to reduce the penetration depth and thus the relative peak intensity of iron, incident angle $(\omega)$ was fixed to 5 .

The cracking mechanisms and the microstructure of the oxide/intermetallic/steel interfaces were investigated by post-mortem metallographic observations and analyses. At the end of the TF test, each specimen was cut and several cross-sectional samples were prepared (different cross section planes). Samples were first mechanically polished and then mirror finished using colloidal silica. Some samples were electrochemically etched using a $10 \%$ chromic acid solution and setting parameters (voltage of $5 \mathrm{~V}$, intensity of $0,8 \mathrm{~A}$ and etching time of $20 \mathrm{~s}$ ). This attack aims to reveal the initial austenitic structure of the steel and the oxide microstructure, by dissolving compounds containing chromium (as the chromium carbides and spinel oxides). A FEI Nova NanoSEM 450 Scanning Electron Microscope was used to observe the interface cross-sections. The chemical composition of coated specimens was analysed by Energy Dispersive Spectroscopy (EDS), using an acceleration voltage of $25 \mathrm{kV}$ before the TF tests ( $\mathrm{Fe} / \mathrm{Al}$ binary system), and of $15 \mathrm{kV}$ after the TF tests $(\mathrm{O} / \mathrm{Cr} / \mathrm{Fe} / \mathrm{Al}$ system).

\subsection{Coating process}

Steel specimens were coated using a CVD process called " $\mathrm{AlCl}_{3}$ Pack Cementation" (PC), to form Fe-Al intermetallic phases in a large temperature range $\left(500-1000^{\circ} \mathrm{C}\right)$ [33-35]. In order to avoid the thermal softening and keep the initial microstructure and hardness of the steel, the coating temperature was selected to be below the second tempering temperature of the steel $\left(605^{\circ} \mathrm{C}\right)$. The TF specimens were buried in a powder mixture $\left(8 \mathrm{Al}-2 \mathrm{AlCl}_{3}-90 \mathrm{Al}_{2} \mathrm{O}_{3}\right)$ consisting of three components: $\mathrm{Al}$ as the metallic source (element to be deposited on the surface), $\mathrm{AlCl}_{3}$
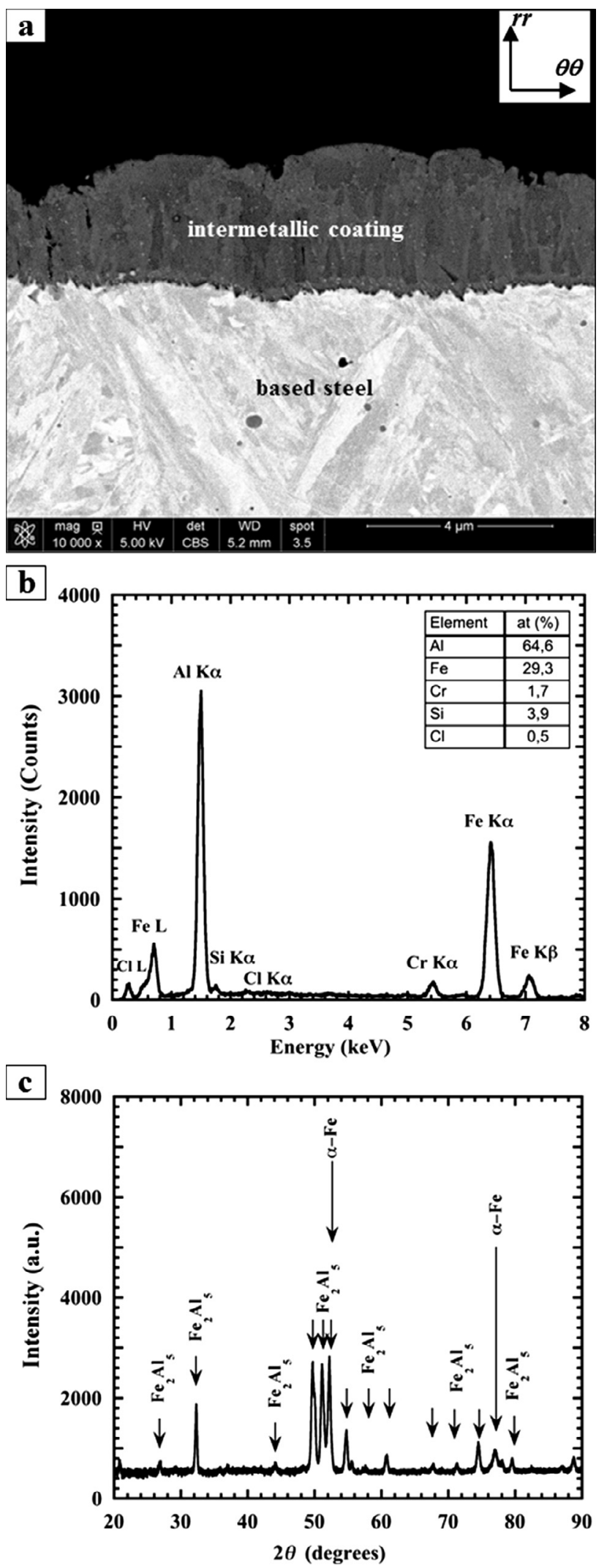

Fig. 4. Coated X38CrMoV5 (AISI H11) steel by $\mathrm{AlCl}_{3}$ Pack Cementation at $500{ }^{\circ} \mathrm{C}$ for $8 \mathrm{~h}$ : cross sectional SEM (BSE) micrograph (a), EDS spectrum performed at $25 \mathrm{kV}$ (b), and XRD pattern from the outer surface, using Co-K $\alpha$ radiation with $\omega=5^{\circ}, \mathrm{V}=40 \mathrm{kV}$ and $\mathrm{I}=40 \mathrm{~mA}$ (c). 
as halide salt activator, and $\mathrm{Al}_{2} \mathrm{O}_{3}$ as inert filler preventing powder sintering. The average particle size of the powder mixture was about $70 \mu \mathrm{m}$. The sealed pack was loaded into a furnace, and cementation was performed for $8 \mathrm{~h}$ at $500{ }^{\circ} \mathrm{C}$ under an inert atmosphere $\left(\mathrm{N}_{2}\right.$ with $\left.5 \% \mathrm{H}_{2}\right)$. The furnace, controlled by a programmable temperature controller, was heated at a rate of $16{ }^{\circ} \mathrm{C} \mathrm{min}{ }^{-1}$ to the required temperature and cooled to room temperature at the same rate [9].

As shown by SEM observations with a Back Scattered Electron (BSE) detector, a compact and homogeneous coating of less than $5 \mu \mathrm{m}$ was formed with a columnar grain structure (Fig. 4a). EDS and XRD analyses revealed that the coating consisted mainly of $\mathrm{Fe}_{2} \mathrm{Al}_{5}$ (Fig. $4 \mathrm{~b}$ and c).

\section{Results}

\subsection{Superficial damage}

\subsubsection{Virgin steel specimens}

In air, a uniform and homogeneous oxide layer forms on the surface of the steel specimens in the early hundreds of TF cycles. Under thermal cycling, the oxide layer begins to crack within the first hundred cycles (600 cycles). Then, a homogeneous and uniaxial network of parallel and regular micro-cracks (uniaxial heat-checking) forms on the surface of the steel from 1500 cycles, with locally a few spalled areas (Fig. 5a). These micro-cracks are oriented perpendicular to the orthoradial axis of the specimen (i.e. to the circumferential stress $\sigma_{\theta \theta}$ ). They propagate through the oxide layer in depth towards the steel and along " $z z$ " direction, reaching the lateral faces of the disc crossing the specimen edge. Beyond 5000 cycles, some micro-cracks (called "secondary") get closed in outer surface and disappear (Fig. 5b). Therefore, the mean apparent inter-crack distance $d$ tends to increase with the number of TF cycles $N$, as shown in Fig. 6 .

In cross-section, it can be observed that the oxide layer formed in air on the virgin steel after 30,000 TF cycles is thick, compact and adherent to the steel. In addition, the oxide scale is multi-layered with inner $\mathrm{Cr}$ rich and outer Cr-poor oxides. Fig. 7 also shows that the micro-cracks propagate from the superficial "heat-checking" into the base steel through the oxide scale. All micro-cracks are filled by inner Cr-poor oxide. The propagation of secondary micro-cracks seems to be limited in the oxide scale. Few micro-cracks propagate in depth, marking thus the initiation phase of steel cracking. The cracks propagating into the steel follow a straight path perpendicular to the " $\theta \theta$ " axis (Fig. 7a). The crack surfaces are oxidized, as the outer surface of the steel, but with decreased thickness towards the crack tip (Fig. 7a).

When the TF test is performed in nitrogen, both the kinetics and the morphology of the oxides are modified. The oxidation is logically

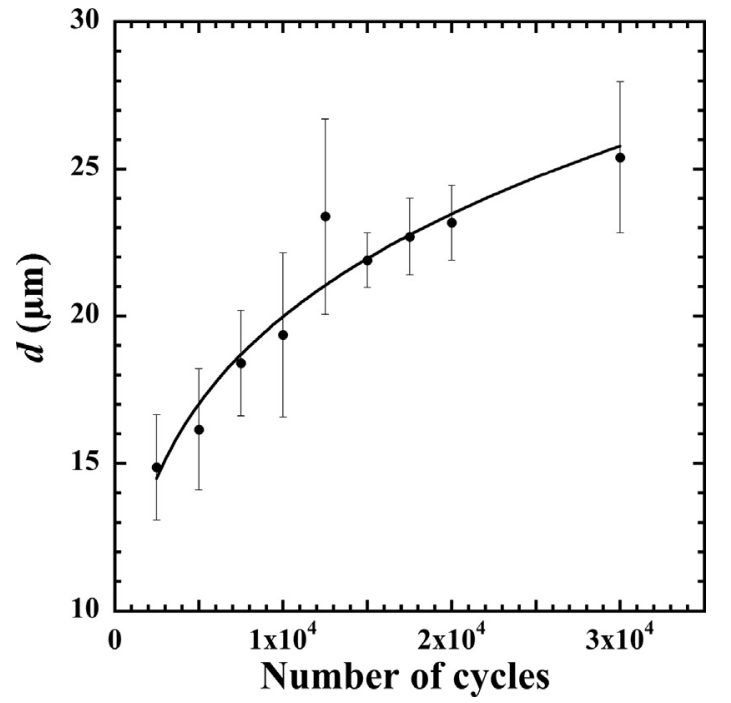

Fig. 6. Evolution versus number of cycles of the mean distance between the micro-cracks $(d)$ formed on the oxidized surface of the virgin steel specimen tested in air.

reduced since the oxygen partial pressure in the test atmosphere is lowered. Furthermore, a thin, laminated and porous oxide scale is observed, which shows a strong tendency to spalling during the early stages of its formation (Fig. 8a). Even if the acicular structure of the superficial oxide differs from that observed in air, the same layers are found. No evidence of heat-checking network is observed and cracking is strictly limited to few areas where the oxide layer breaks markedly (Fig. 8b). In cross-section, most of the cracks appear thin, with a slightly opened crack tip, and are filled with oxide up to a very shallow depth, indicating that a few ppm of oxygen is sufficient to enable a crack propagation mechanism assisted by oxidation. Although the propagation paths are meandering (Fig. 9), it remains perpendicular to the " $\theta \theta$ " axis at macroscopic scale.

\subsubsection{Coated steel specimens}

In air, the surface of the coated specimen is first damaged by a uniaxial "heat-checking" (Fig. 10a), which is quite similar to that the one observed on virgin steel tested in air (Fig. 5a). However, it should be noted that the micro-crack network appears distinctly later, i.e. after 2500 cycles instead of 600 cycles for the virgin steel tested in air. Then, the oxidized areas (appearing in white on the micrographs) emerge through the micro-cracks and tend to completely fill the cracks at

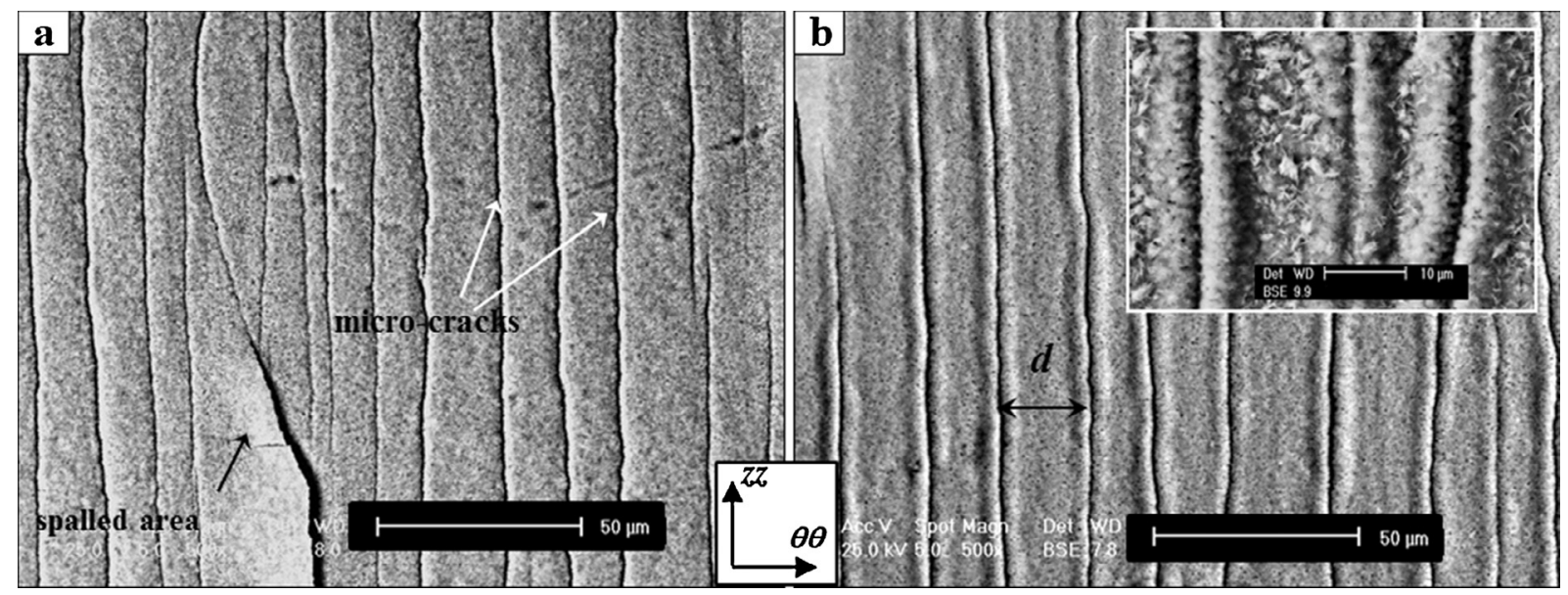

Fig. 5. SEM (BSE) micrographs of the surface of the specimen tested in air after 1500 TF cycles (a), and detailed view of the homogenous uniaxial "heat-checking" network after $5000 \mathrm{TF}$ cycles (b). 


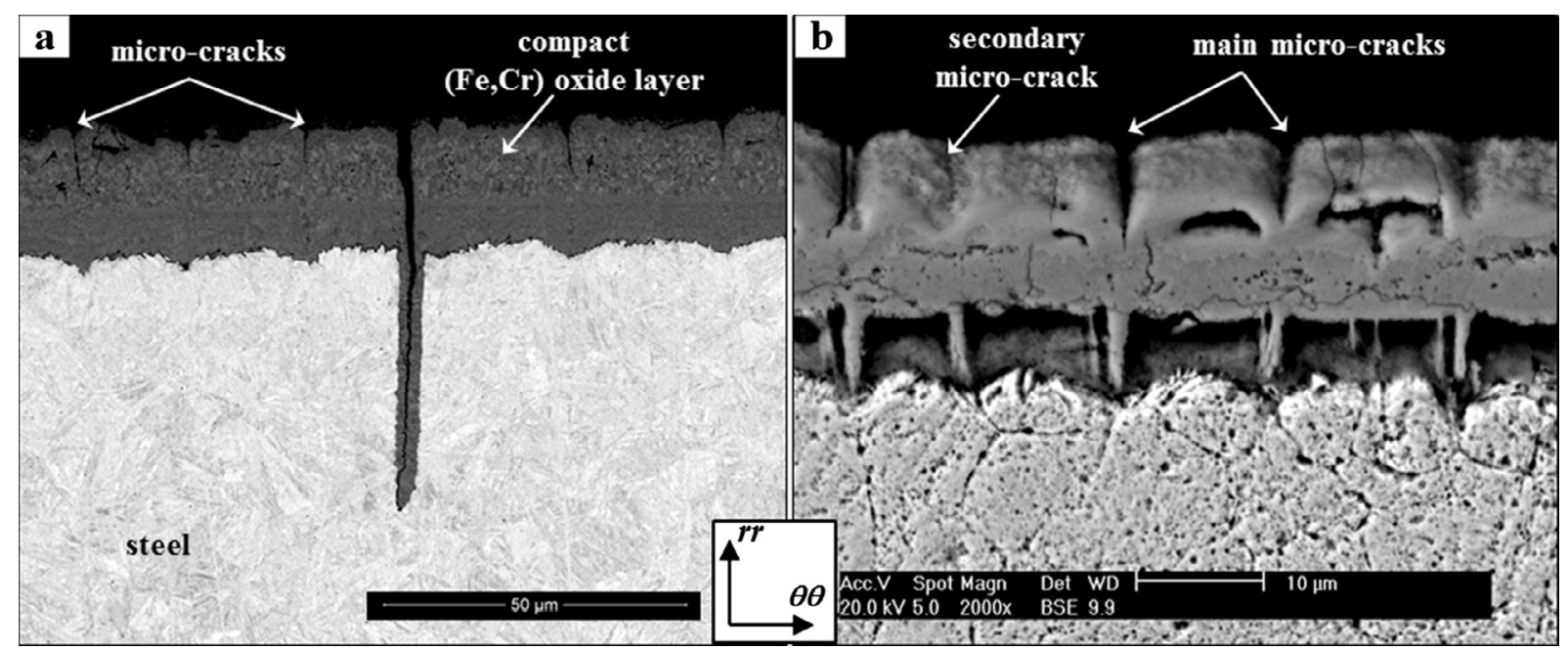

Fig. 7. SEM (BSE) micrographs in cross section of the virgin specimen tested in air after 30,000 TF cycles, before (a) and after electrolytic etching in chromic acid (b).

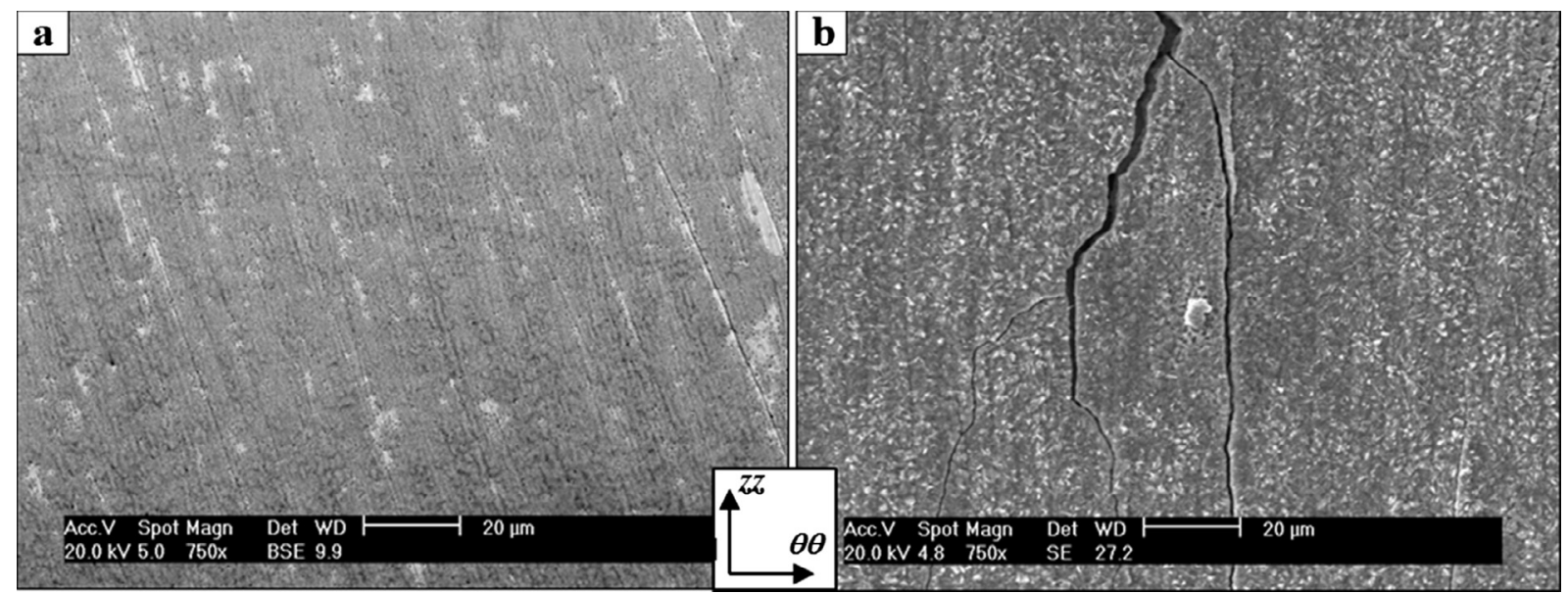

Fig. 8. SEM (BSE) micrographs of the outer surface of the specimen tested in nitrogen, showing a porous and thin oxide layer after 10,000 TF cycles (a), and detailed view of the isolated cracks that develop after 25,000 TF cycles (b).

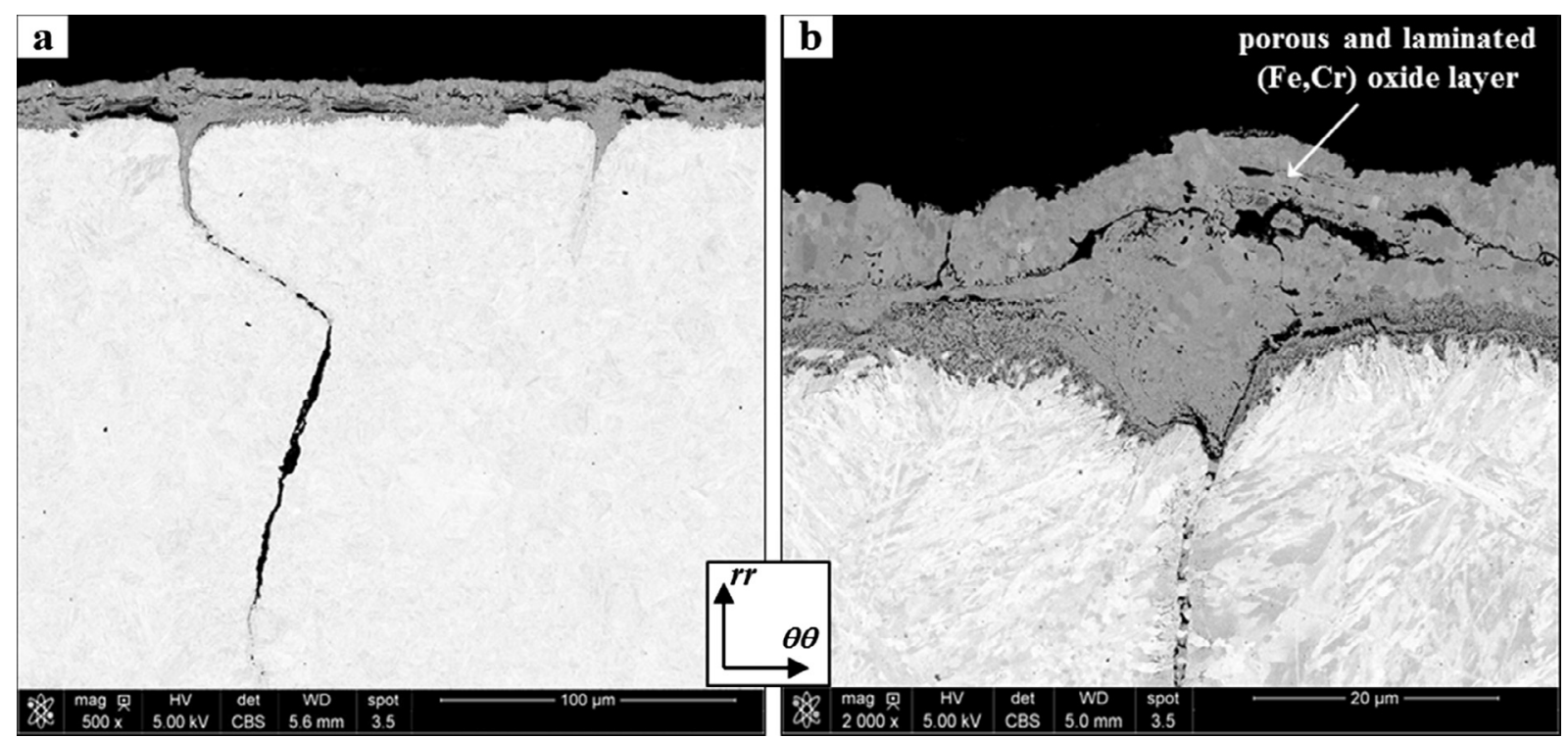

Fig. 9. SEM (BSE) micrographs in cross section of the virgin specimen tested in nitrogen after 40,000 TF cycles (a) and detailed view showing the superficial oxide layer (b). 


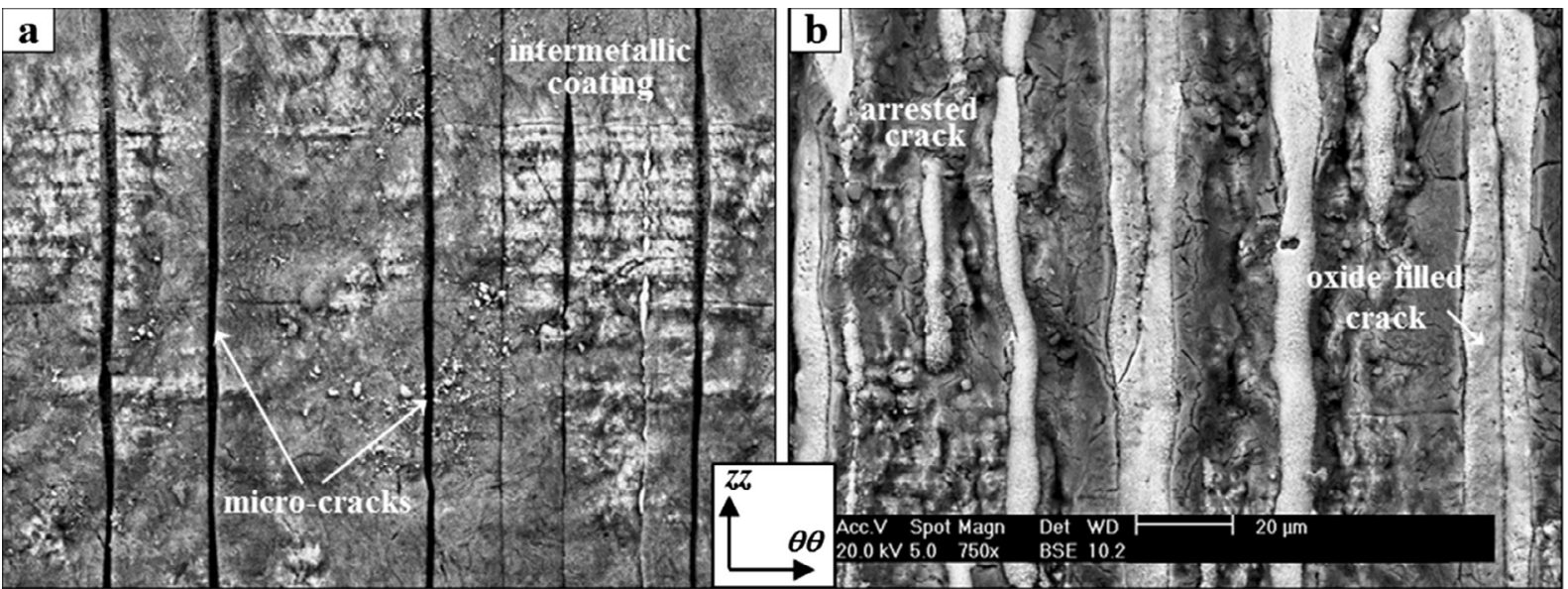

Fig. 10. SEM (BSE) micrographs of the surface of the coated specimen tested in air after 5000 TF cycles (a), and detailed view of the homogenous uniaxial "heatchecking" network after 30,000 TF cycles (b).

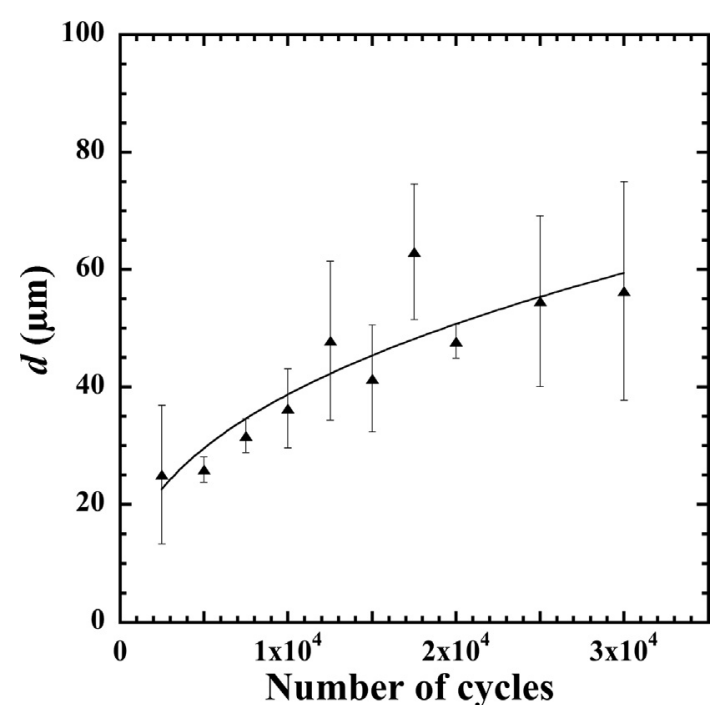

Fig. 11. Evolution versus number of cycles of the mean distance $(d)$ between the micro-cracks formed on the coated specimen tested in air.

higher number of TF cycles $N$ (Fig. 10b). Some micro-cracks open while others seem completely closed. As previously observed for virgin steel in air, the mean inter-crack distance $d$ increases by increasing $N$ (Fig. 11). As can be seen in cross-section, most of the micro-cracks propagate in the steel, to a depth of a few tens of micrometres (Fig. 12a and b). These cracks, which are entirely filled with oxide, are V-shaped. It is also observed that the external surface is particularly rough, due to oxide protrusions through the micro-cracks (Fig. 12b). Some microcracks stop to a few micrometres in depth and seem to be closed, thus explaining the increase of $d$ with $N$.

Cross sectional observations reveal that the microstructure of the $\mathrm{Fe} / \mathrm{Al}$ intermetallic coating changes under the effect of thermal and thermo-mechanical loadings. The evolution of the interface and the intermetallic coating (that is transformed into a multilayer) is particularly well highlighted by EDS analyses (Fig. 13) and the microstructure (Fig. 14a). XRD analyses (Fig. 14b) still reveal the presence of $\mathrm{Fe}_{2} \mathrm{Al}_{5}$, but also $\mathrm{Fe}(\mathrm{Al}), \mathrm{FeAl}$ and traces of $\mathrm{Fe}_{3} \mathrm{Al}, \mathrm{FeAl}_{3}$ and $\mathrm{FeAl}_{2}$. The interdiffusion of chemical species on the coating free surface and through the micro-cracks (into the steel) induces the formation of $\mathrm{Al}_{2} \mathrm{O}_{3}$, and $\mathrm{Fe}_{2} \mathrm{O}_{3}, \mathrm{Fe}_{3} \mathrm{O}_{4}$ and $(\mathrm{Fe}, \mathrm{Cr})_{3} \mathrm{O}_{4}$, respectively. After $30,000 \mathrm{TF}$ cycles, the total thickness of the modified coating and steel surface can reach $10 \mu \mathrm{m}$.

Under nitrogen, the superficial "heat-checking" network is heterogonous with shorter and less opened micro-cracks, leading to a lower apparent surface density than in air (Fig. 15a). Oxide still grows inside the micro-cracks (appearing in white in Fig. 15b), but in smaller quantities than in air. Cross-sectional observations reveal that these micro-cracks propagate in depth following a sinuous path (Fig. 16a), and that the micro-crack tips are less opened than in air (Fig. 16b). In addition, some thin and short cracks initiate into the steel and propagate towards the surface and the bulk along planes perpendicular to the

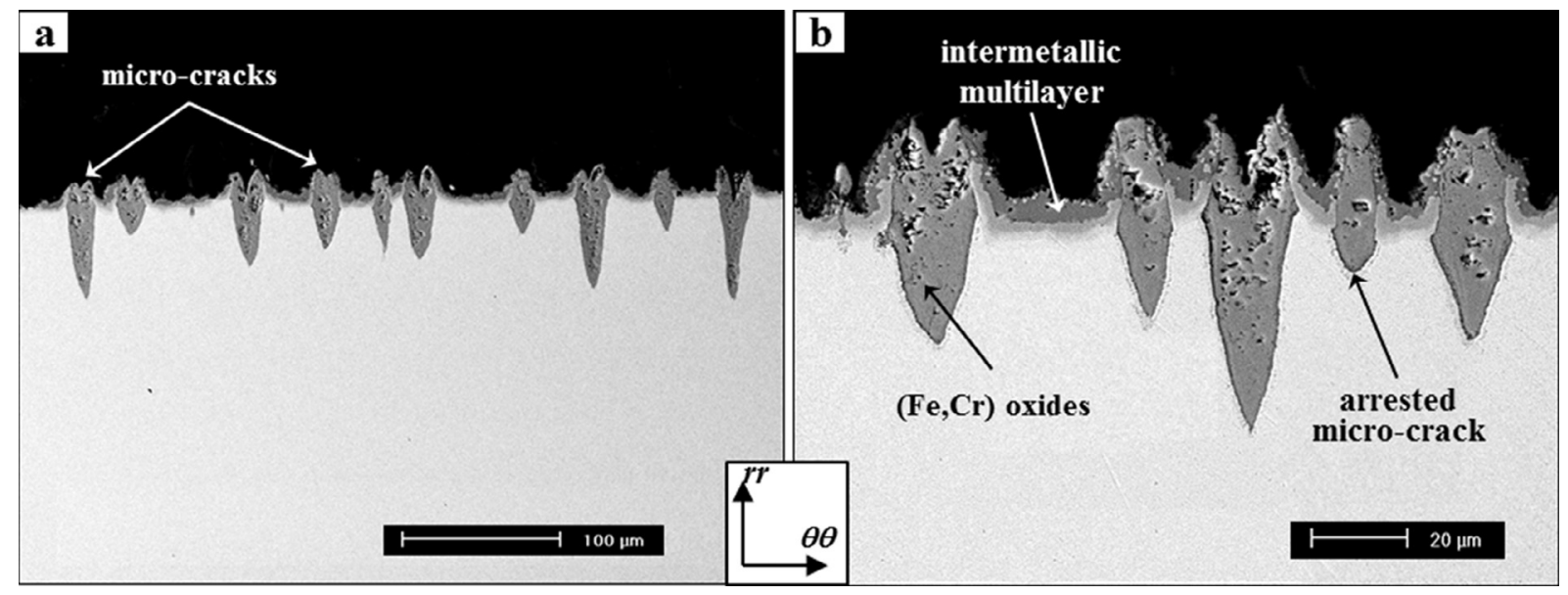

Fig. 12. SEM (BSE) micrographs in cross-section of the coated specimen tested in air after 30,000 TF cycles (a), and enlarged view of the specimen surface (b). 


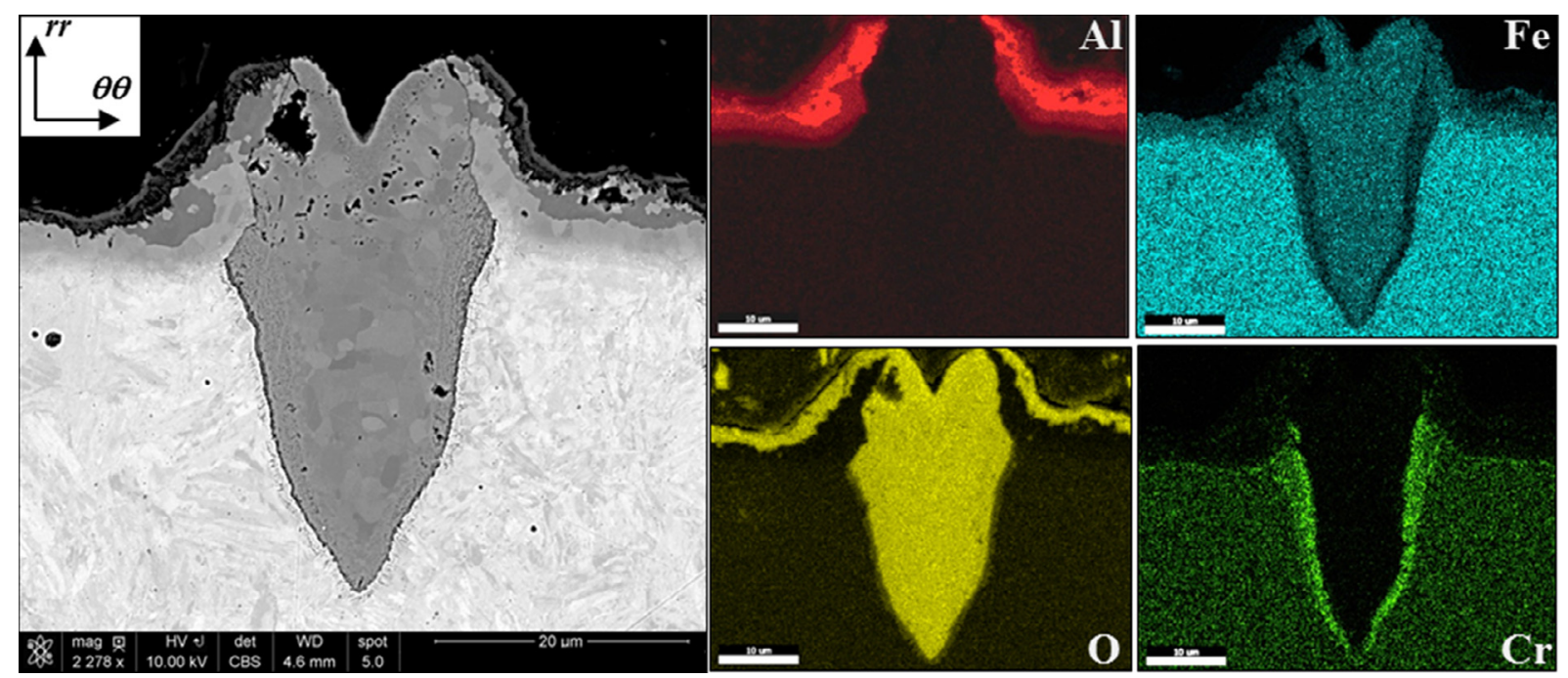

Fig. 13. SEM (BSE) micrograph in cross section of a micro-crack formed on the coated specimen tested in air after 30,000 cycles, and its associated ESD elementary maps showing the distribution of $\mathrm{Al}, \mathrm{Fe}, \mathrm{O}$ and $\mathrm{Cr}$ (40 frames, $\mathrm{V}=15 \mathrm{kV}$, time constant $=13 \mu \mathrm{s}$ ).

" $\theta \theta$ " axis. It must be emphasized that this was never observed for TF tests carried out in air.

\subsection{TF life and crack propagation mechanisms}

The lifetime data corresponding to the required numbers of TF cycles for micro-crack initiation and macro-crack growth (using two different criteria of crack depth, as described in Section 2.3) are reported in Table 3. It indicates that in air, the micro-crack initiation is strongly delayed (by almost a factor 4) in the intermetallic layer compared to the oxide scale. However, in nitrogen, the crack initiation starts later in the intermetallic layer, with a difference of 2500 cycles compared to the same test in air.

The propagation curves plotted in Fig. 17a and b represent the evolution of the depth of the main crack for the virgin and coated steels, respectively. In all cases, the TF crack growth follows a classical sigmoidal trend, with acceleration just after initiation followed by a stabilization of the propagation rate around of $0.35 \mu \mathrm{m} /$ cycle, and then arrest for a crack depth greater than $2 \mathrm{~mm}$. On the other hand, the propagation rate of cracks between 0.5 and $2 \mathrm{~mm}$ seems to be rather independent from the test atmospheres. The depth of macro-cracks varies depending on the test conditions and the number of macro-cracks propagating in each specimen. In fact, for the virgin steel tested in air and coated specimens tested in both atmospheres, two diametrically opposed macro-cracks (main cracks) propagate in the disc. After 20,000 TF cycles, other secondary macro-cracks propagate in each specimen. However, both the main and secondary macro-cracks started simultaneously in the virgin steel tested in nitrogen.

Fractographic analyses show that crack surfaces are oxidized and rough. Different shapes are observed for short cracks $(a<0.5 \mathrm{~mm})$ propagating in the edge specimen and long cracks ( $a>0.5 \mathrm{~mm}$ ) propagating in the disc. The front of short cracks is longer in surface than in depth (Fig. 18a), whereas the long crack front is deeper inside the disc (Fig. 18b). On the non-oxidized areas of the steel surface, crack propagation follows a "zig-zag" path along symmetrical planes inclined at $45^{\circ}$ to the loading axis (Fig. 19a). At the macroscopic scale, cracks propagate in depth in mode I, along a plane perpendicular to the circumferential " $\theta \theta$ " axis. The crack propagation usually follows a transgranular mechanism (Fig. 19b), but evidence of inter-granular propagation can also be observed occasionally (Fig. 19c).
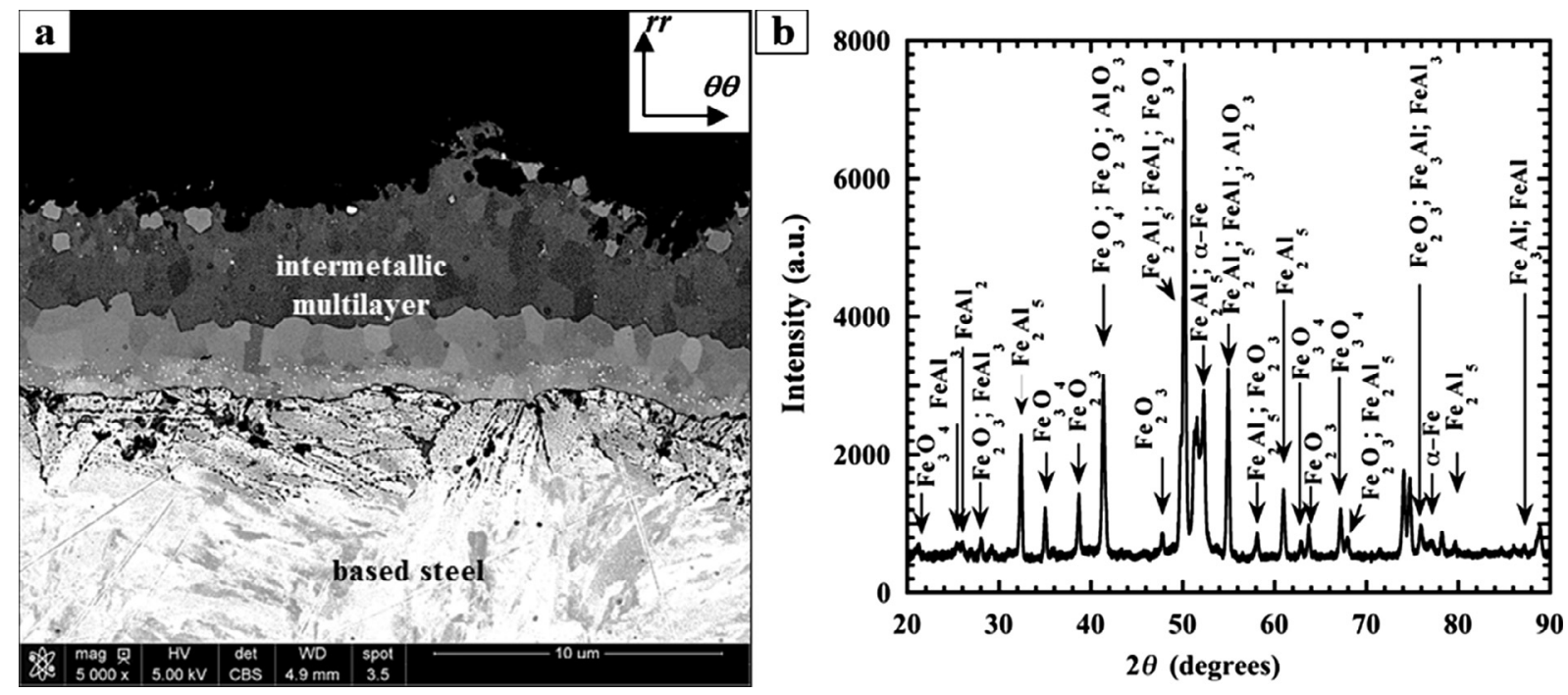

Fig. 14. Cross-sectional SEM (BSE) micrograph (a) and XRD pattern (b) of the coated specimen tested in air after 30,000 TF cycles. The XRD analysis was performed from the outer surface of the specimen (using Co-K $\alpha$ radiation with $\omega=5^{\circ}, V=40 \mathrm{kV}$ and $I=40 \mathrm{~mA}$ ). 


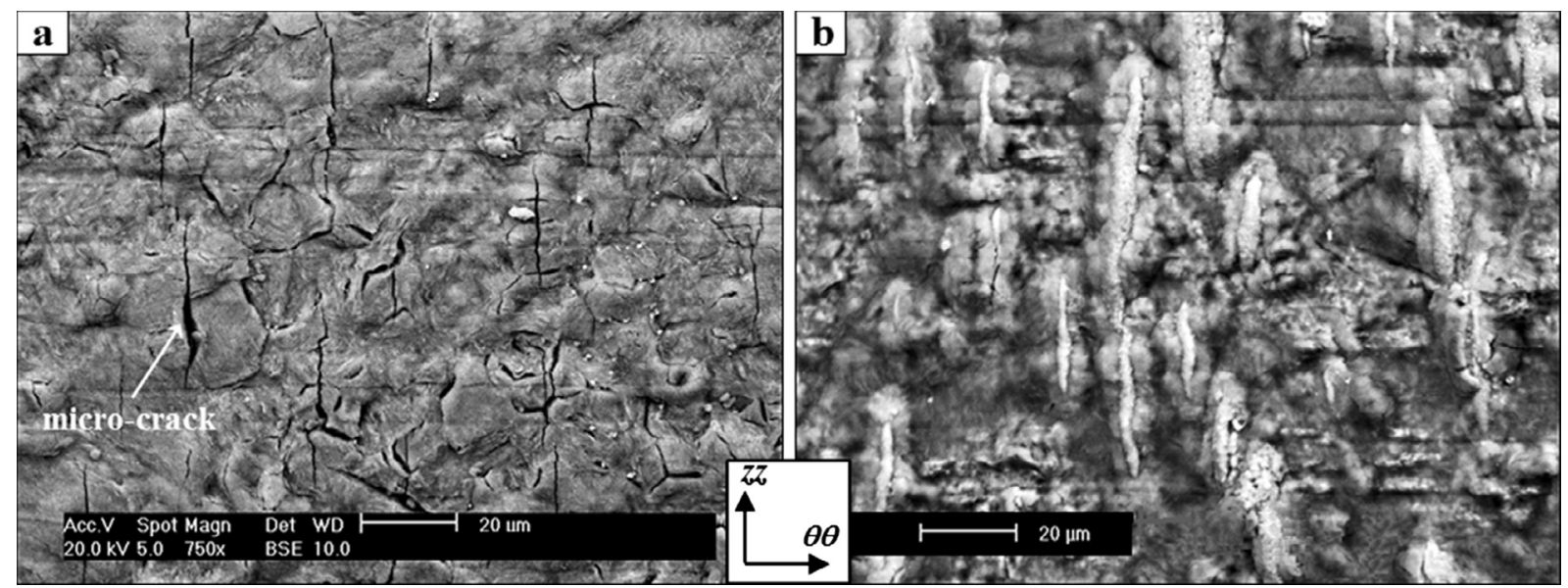

Fig. 15. SEM (BSE) micrographs of the surface of the coated specimen tested under nitrogen after 5000 TF cycles (a), and detailed view of the non-uniform uniaxial "heat-checking" network after 30,000 TF cycles (b).

\section{Discussion}

During the TF test, the specimen is self-constrained since the "free" thermal expansion of the surface is hindered by the bulk, which is at lower temperature. Therefore, each element of the specimen undergoes cyclic strains and associated stresses resulting from the thermal transients. The external surface of the steel is thus subjected to a thermomechanical stress-strain hysteresis loop, and goes into compression during attempted expansion (heating phase) and into tension during attempted contraction (cooling phase) [36,37]. Since the oxide or intermetallic layer is strongly bonded to the substrate, it undergoes the same thermo-mechanical loadings imposed to the steel surface. Other stresses (related to geometric factors, material heterogeneity or layer growth, etc.) are superposed to thermal stresses induced by the substrate [38]. The local mechanical incompatibility, generated by the thermal mismatch between the substrate and the multilayered coating of different coefficients of thermal expansion [39,40], significantly impacts the thermo-mechanical loading on the surface. The sub-surface also undergoes metallurgical modifications, along the thickness and in the composition of the layer. In addition, the thermo-mechanical loading induces cyclic softening of the steel, phenomenon that has been widely reported for tool steels $[18,28,31,41,42]$. Whether or not the specimen is coated, the damage usually initiates first in the superficial layer (composed of the intermetallic layer and/or the steel surface). After a critical number of cycles (depending on the amplitude and rate of the thermal cycle and environmental conditions), cracks initiate and propagate under mode I along the circumferential " $\theta \theta$ " axis [36].
Table 3

Comparison of the lifetime of virgin and coated X38CrMoV5 (AISI H11) steel under thermal fatigue at $T_{\max }=650{ }^{\circ} \mathrm{C}$, in air and nitrogen.

\begin{tabular}{lllll}
\hline Specimen & $\begin{array}{l}\text { Test } \\
\text { atmosphere }\end{array}$ & $\begin{array}{l}\text { Number of } \\
\text { cycles for } \\
\text { micro- } \\
\text { crack } \\
\text { initiation }\end{array}$ & $\begin{array}{l}\text { Number of cycles } \\
\text { (crack } \\
\text { depth }=1 \mathrm{~mm} \text { ) }\end{array}$ & $\begin{array}{l}\text { Number of cycles } \\
\text { (crack } \\
\text { depth }=2 \mathrm{~mm} \text { ) }\end{array}$ \\
\hline Virgin steel & Air & 600 & 11,000 & 13,500 \\
& $\mathrm{~N}_{2}$ & - & 25,000 & 28,000 \\
Coated steel & Air & 2500 & 14,000 & 18,500 \\
& $\mathrm{~N}_{2}$ & 5000 & 16,000 & 18,500 \\
\hline
\end{tabular}

Various damage mechanisms are involved depending on the nature of the specimen (virgin or coated steel) and the TF test environment (air or nitrogen), as detailed below.

\subsection{Damage mechanisms}

It was shown that the oxide layer formed on the virgin steel is always composed, of superficial hematite $\left(\mathrm{Fe}_{2} \mathrm{O}_{3}\right)$, magnetite $\left(\mathrm{Fe}_{3} \mathrm{O}_{4}\right)$ and inner spinel $(\mathrm{Fe}, \mathrm{Cr})_{3} \mathrm{O}_{4}[9,13,18,27]$, whatever the test atmosphere. The thickness proportions of these different oxide layers were estimated at 20,40 and $40 \%$, respectively. In air, the oxide was compact and homogeneous, and its surface was damaged very early by a "heatchecking" network. This mode of cracking, by initiation and

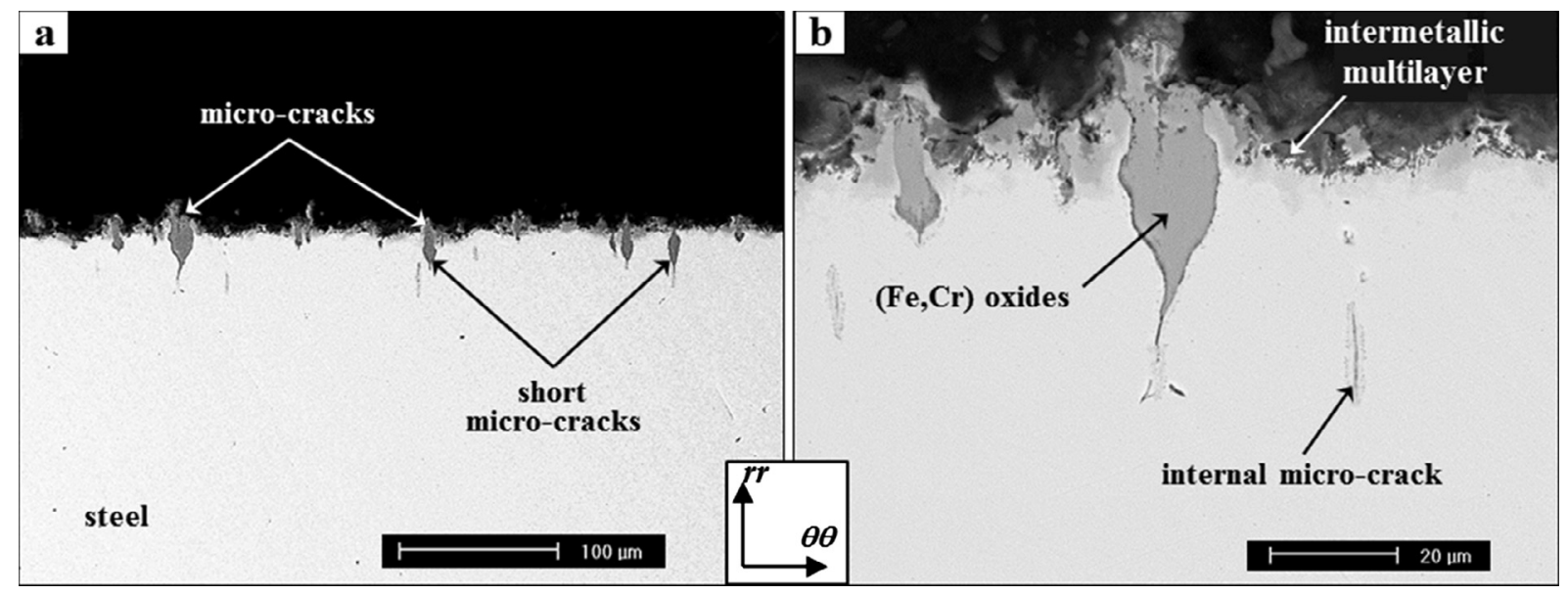

Fig. 16. SEM (BSE) micrographs in cross-section of the coated specimen tested under nitrogen after 30,000 TF cycles (a), and enlarged view of the micro-cracks (b). 
a)

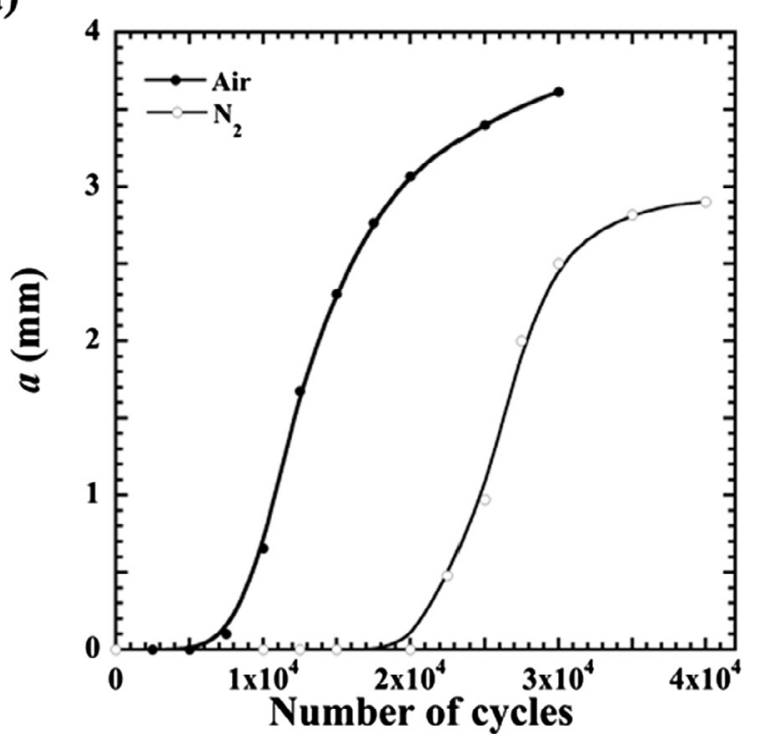

b)

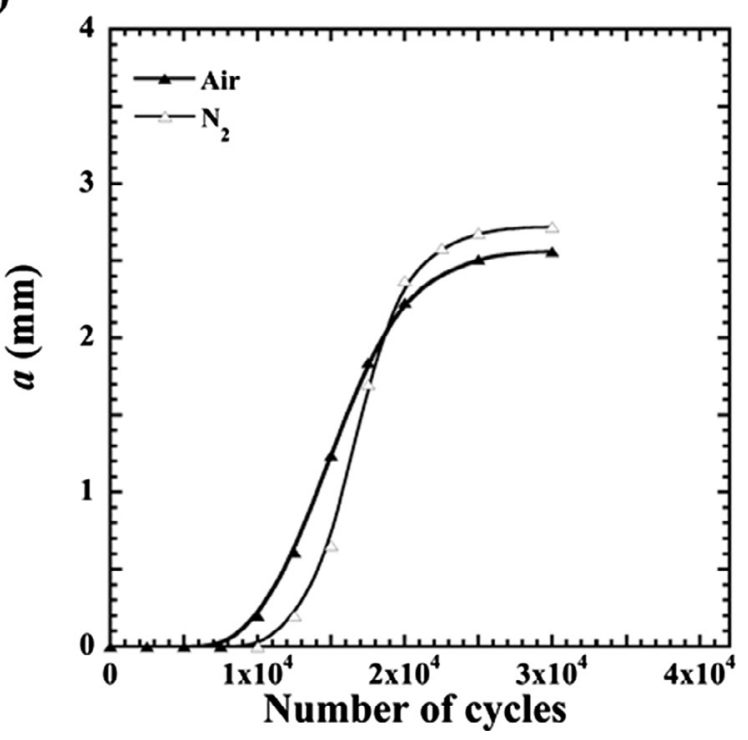

Fig. 17. Propagation curves of the main cracks in air and nitrogen, respectively for virgin (a) and coated (b) steel specimens.

propagation of through-scale micro-cracks perpendicular to the steel/ coating interface, is generally attributed to the hard coating failure under tension [43-46]. Schütze et al [47] proposed an oxide scale failure mechanism depending on applied strain, scale thickness and defect sizes. Accordingly, the first through-scale cracks developed from pre-existing defects in regions with high stress concentration, when critical thickness and tensile strain are reached. At low temperature (corresponding in our TF tests to the maximum stress $\sigma_{\max }$ ), the accommodation of tensile stress was achieved by oxide cracking when this stress exceeded, locally, the elastic limit of the oxide. The brittle breakdown of the oxide into a finite number of segments led in surface to the formation of homogenous and dense "heat-checking" network, propagating on the surface along " $z z$ " axis and in depth towards the steel. The growth of micro-cracks through the inner oxide reduced the oxide scale cross section (distance between the free surface and the steel). Oxidation was thus accelerated through the micro-cracks, which represent preferential diffusion paths. The outward migration of iron cations, resulting in the formation of magnetite on the micro-crack surfaces, partially filled the micro-cracks. The inward diffusion of oxygen caused the penetration of oxide into the steel around the crack tip, leading to the formation of magnetite, and then spinel when the micro-crack propagated beyond a Cr-depleted zone (Fig. 7b). In fact, some micro-cracks stopped because screened by the deeper neighbouring micro-cracks, which locally deformed the orthoradial stress fields at the blunted tips. These arrested micro-cracks disappeared from the surface because covered by hematite, and seemed completely filled by magnetite in depth. Indeed, the internal growth of the oxide reduced the distance between the free surface and the steel surface normalizing thus the oxidation kinetics of the steel in the cracked and uncracked oxide zones. The inside protrusion of oxide was prevented or stopped, since the preferential diffusion was decelerated. Therefore, the healing oxide partially restored the protective action of the layer, resulting in a decrease in micro-crack density (Fig. 6). Meanwhile, in-depth propagating micro-cracks amplified local stress fields and, in conjunction with local thermo-mechanical softening and oxidation, caused nucleation and propagation of macro-cracks (especially on the first hundred micrometres). Previous investigations [27] suggested a link between superficial micro-cracks and macro-cracks propagating in depth. When the crack propagated in the steel, its fresh surfaces in contact with air oxidized in the same way as the free surface of the steel. A compact multilayer oxide grew on each crack lip, with a decreasing thickness towards the crack tip where the oxidation kinetics was less important than at the top of the crack (decrease in depth of oxidation temperature and time). Under nitrogen, the oxide layer formed after a large number
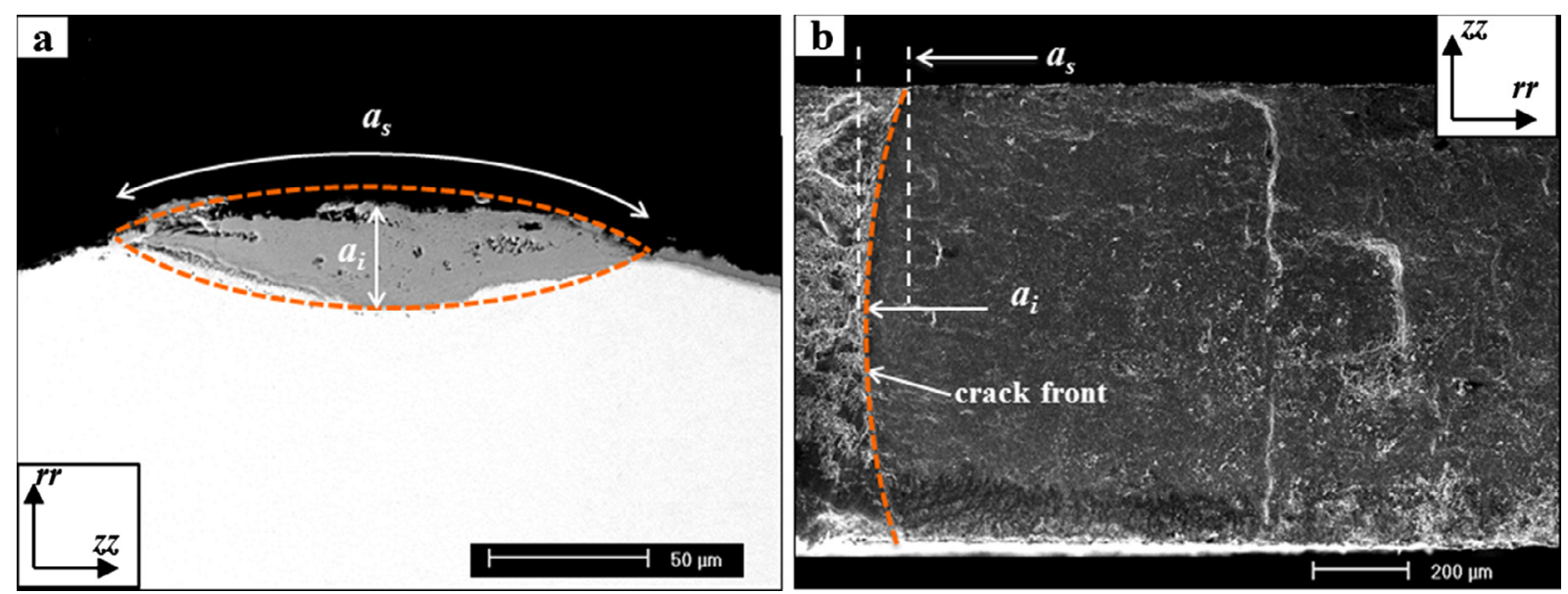

Fig. 18. Post-mortem SEM observations showing the elliptical shape of the short cracks propagating in the specimen edge (a), and the curved front of the crack propagating in the disc (b) ( $a_{s}$ and $a_{i}$ are the size of the crack, respectively on surface and in-depth). 


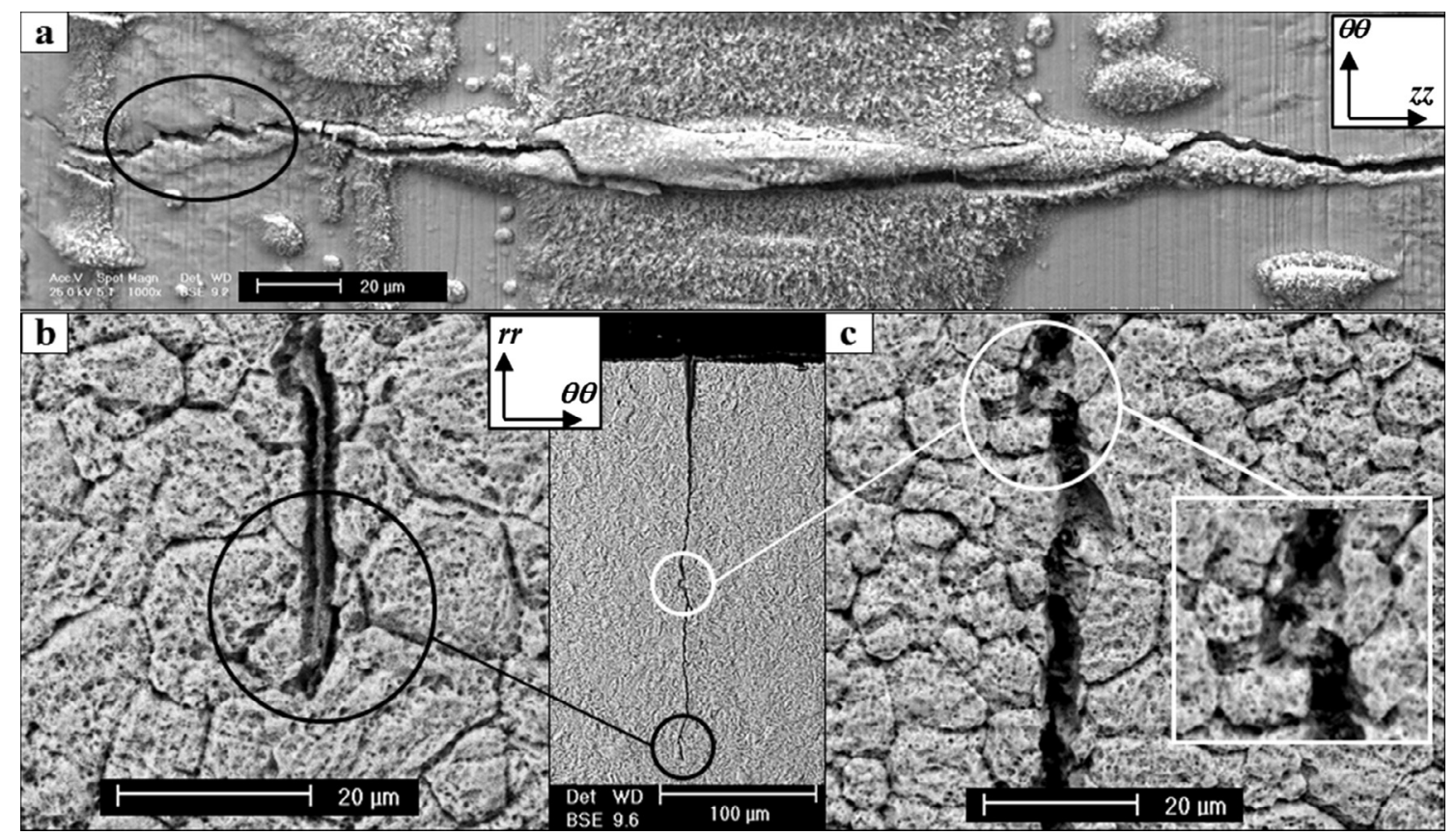

Fig.19. Different mechanisms of crack propagation observed in the specimen tested under inert atmosphere at $T_{\max }=650{ }^{\circ} \mathrm{C}$ : “zig-zag" propagation path observed on the non-oxidized areas of the steel surface (a); trans-granular (b) and inter-granular in depth propagation (c) of a short crack.

of cycles was thinner and more porous than in air. The deformation of the superficial layer, caused by the thermo-mechanical stresses, led to development of surface wrinkling, but without the formation of a "heatchecking" network (even after 10,000 cycles). This should be mainly related to the mechanical behaviour of the porous oxide layer and its weak bound with substrate. Accordingly, oxide layer accommodated the thermo-mechanical loadings by deforming rather than cracking, unlike the compact oxide or intermetallic layer.

The mechanism of surface micro-crack formation observed for the coated steel was close to that found for the compact oxide grown in air, with however some changes in the damage sequence. First, the microstructure of the initial intermetallic coating evolved to a complex multilayered intermetallic and oxide, due to the thermally activated diffusion of iron, aluminium and oxygen at high temperature. The new phases identified in this multilayer were in agreement with the $\mathrm{Fe}-\mathrm{Al}$ equilibrium diagram and the literature [48-51]. Then, the micro-cracks propagated through the modified intermetallic layer both toward the steel (in depth) and along "zz" axis (on the surface), as observed in the compact oxide scale formed on virgin specimens tested in air. However, a difference in the morphology of micro-cracks was observed depending on the test atmosphere (air or nitrogen). In air, greater oxidation increased the propagation rate of the superficial micro-cracks along the "zz" axis to achieve a uniform and dense heat-checking network. In both atmospheres, the outside protrusions of the iron oxides through the micro-cracks caused the uplift of the intermetallic layer without inducing breaking, testifying to the ductility of some of iron aluminium intermetallic phases, especially at high temperature [50].

\subsection{Effect of the heat-checking network and oxidation on the TF lifetime}

In air, both virgin and coated $\mathrm{TF}$ specimens showed premature cracking with the growth of two main macro-cracks in the bulk steel, while under nitrogen the virgin steel simultaneous exhibited multicracking at higher number of cycles. The premature cracking of steel could be initiated, by the concentration of stress fields at the tip of the micro-cracks, from the "heat-checking" network that develops on the oxide growing in air and in the intermetallic coating.

Moreover, the intermetallic coating increased the TF lifespan by about $30 \%$ (for a crack length of $1 \mathrm{~mm}$ ), compared to the virgin steel tested in air. This difference would come from the characteristics of the superficial layer, and in particular the intrinsic properties of $\mathrm{Fe}-\mathrm{Al}$ intermetallics showing a better TF durability than the Fe-Cr oxides. This was further corroborated by measurements of the "heat-checking" network density (inversely proportional to the distance between the micro-cracks), which was twice as small on the coated specimens and even less by increasing the number of cycles. Therefore, a better resistance to TF "heat-checking" of the superficial layer would increase the lifetime of the steel. However, when the surface was free off a hard coating (such as an oxide or intermetallic layer), the lifetime was much longer because of the high ductility of the steel. Indeed, for the virgin specimen tested under nitrogen, the surface element could be considered composed by the steel only (by neglecting the mechanical role of the oxide, here as a porous and unbound layer).

On the other hand, the TF lifetime of the coated specimen was slightly increased under nitrogen, due to the slower growth of the surface "heat-checking" network. This clearly shows the predominant role of oxidation in both the development of the surface "heatchecking" network and the propagation of micro-cracks through the intermetallic coating. However, oxidation seemed less significant in the premature cracking of the coated steel, with a difference of only $12 \%$ on the number of cycles to initiation between TF tests in air and nitrogen.

For all TF tests, the crack propagation curves showed a fairly similar kinetics of the main macro-cracks (for $a$ between 0.5 and $2 \mathrm{~mm}$ ). The effect of oxidation on the crack propagation rate in the base steel was thus less obvious, although it was significant for propagation mechanisms of short cracks. Oxidation should however influence the crack propagation kinetics, especially at the top of the specimen exposed to maximum temperatures. Indeed, it was shown that the cracks were more opened in air than under nitrogen, suggesting a higher crack propagation rate in air. Unfortunately, this could not be highlighted for short cracks $(a<0.5 \mathrm{~mm})$ in the current propagation curves, due to the limitations of the measurement method (projections along " $r r$ " axis of the crack trace appearing on the lateral faces). The criterion of crack sizing in the disc part should be different than in the specimen edge, where the crack shape was elliptical with two axes (Fig. 18a). In fact, due to the semi-cylindrical geometry of the specimen edge, crack 
propagation was faster on the surface than in depth. Once the cracks reached the lateral faces of the specimen (for $a>0.5 \mathrm{~mm}$ ), the crack propagation rates on surface and in depth became uniform and the measured crack $\left(a_{\mathrm{s}}\right)$ were similar in both lateral sides (Fig. 18b). However, the crack front remained slightly curved inside the specimen where the crack propagated under plane strain, while it propagated under plane stress on the surface. The temperature drops along the depth where the oxidation became less important and its effects on the crack propagation were negligible. In both atmospheres, the propagation kinetics were thus comparable for $a$ between 0.5 and $2 \mathrm{~mm}$, as previously seen in propagation curves. Nevertheless, it was clearly demonstrated that both the crack arrest and the total number of macrocracks propagating in the specimen depended on the test conditions. Thermo-mechanical simulations showed that by increasing inward crack length, the J-integral drops $(a>2 \mathrm{~mm})$ because of the attenuation of thermal gradients and thermal stresses in depth $[9,36]$. This explains the S-shape of the TF crack propagation curves. These simulations also led to investigate the interaction between the primary and secondary cracks, and showed that the J-integral decreases by increasing the number of cracks. This can explain the crack arrest at shallower depth for the virgin steel tested in nitrogen, where more than several cracks propagated simultaneously in the disc.

\subsection{Tool damage in HPDC}

In HPDC, the moulds are subjected to fast cyclic thermal transients in a particularly corrosive environment (contact with molten aluminium and air). Damage mechanisms are involved by a complex interaction between TF and corrosion (Fig. 1b-e), close to that observed from TF tests of intermetallic coated and virgin specimens in air. All observations of cracks in HPDC dies reveal such patterns [9,52-56]. In die areas prone to aluminizing, TF damage should thus be controlled by:

- the ability of the lubricant to remain on the die surface, in order to fully play its protective role as a chemical and physical barrier against oxidation, aluminizing (Fig. 1a) and wear;

- aluminizing kinetics that is mainly controlled by the die contact temperature at the location where aluminium impinges and attacks the die, and by shot number (contact duration);

the intermetallic cracking and the nucleation of the crack in the die surface.

One question remains regarding a potential critical thickness and the composition of the intermetallic layer, before any cracking might occur. This could be investigated through TF tests on specimens with different coating thicknesses, or by providing an aluminium-rich test environment allowing a continuous growth of the intermetallic layer (in the same way as the oxide increases on a virgin specimen during a test in air). The growth of both the oxide and the intermetallic layers is controlled by diffusion, which is a thermally activated phenomenon. At $650{ }^{\circ} \mathrm{C}$, the rate constants $\left(k_{p}\right)$ for the oxidation of X38CrMoV5 (AISI $\mathrm{H} 11$ ) in air and its aluminizing in a liquid AlSi9Cu3 (A380) bath are equal to $9.1410^{-2}$ and $2.0 \mu \mathrm{m} \mathrm{s}^{-0.5}$, respectively [9]. Besides, it was shown that the intermetallic layer acts as a chemical barrier to oxidation (and vice versa), and that the oxide promotes a denser network of micro-cracks, which leads to premature cracking of the steel. As the aluminizing kinetics is ten times higher than the oxidation rate (Fig. 1b and c), it would therefore be detrimental to the dies even if the intermetallic layer showed better FT behaviour. Using HPDC mould under an inert atmosphere being hardly conceivable for practical reasons, hard coating could be a good solution to protect the mould surface, as evidenced by many studies on this topic [11,57-62]. To be effective, the coating should meet three criteria: be compatible with the substrate and be ductile enough to avert TF cracking, be chemically stable to prevent corrosion, and be hard enough to avoid damage by wear.

\section{Conclusion}

The effect of the interaction between aluminium and HPDC dies resulting in the formation of intermetallics - on the thermal fatigue (TF) behaviour of X38CrMoV5 (AISI H11) hot work tool steel is investigated. A new experimental approach is proposed to study the interaction between these different damage mechanisms, using virgin and coated specimens by CVD pack-cementation at $500{ }^{\circ} \mathrm{C}$.

The microstructure of the superficial layer undergoes chemical and microstructural evolution during TF cycles, which activates the diffusion of chemical elements $(\mathrm{O}, \mathrm{Al}, \mathrm{Fe}, \mathrm{Cr})$ through the different interfaces. The oxide layer which forms on virgin steel specimens is much thicker, homogenous and compact in air than in nitrogen. On coated specimens, the intermetallic layer, initially composed of $\mathrm{Fe}_{2} \mathrm{Al}_{5}$, evolves to a complex multi-phased layer consisting of new intermetallic phases ( $\mathrm{Fe}_{3} \mathrm{Al}, \mathrm{FeAl}, \mathrm{Fe}(\mathrm{Al}), \mathrm{FeAl}_{2} \mathrm{Fe}_{2} \mathrm{Al}_{5}$ and $\mathrm{FeAl}_{3}$ ) and oxide compounds $\left(\mathrm{Fe}_{2} \mathrm{O}_{3}, \mathrm{Fe}_{3} \mathrm{O}_{4},(\mathrm{Fe}, \mathrm{Cr})_{3} \mathrm{O}_{4}\right.$ and $\left.\mathrm{Al}_{2} \mathrm{O}_{3}\right)$.

The mechanisms of the crack initiation depend on oxidation and the surface layer properties. In air, a micro-crack network forms on the surface of both virgin and coated specimens after a few hundred to thousand TF cycles. The heat-checking network is less dense on the coated specimen, while it is non-existent on the virgin steel since the oxide layer is too thin and porous to initiate micro-cracks. Preferential oxidation by short-circuit diffusion of the base steel leads to the propagation of the heat-checking network in the steel. In addition, the micro-crack propagation through the intermetallic layer is assisted by oxidation. The intermetallic coating delays the steel cracking and increases the TF life of the steel, due to its better TF durability. Under nitrogen, oxidation is greatly reduced and micro-crack initiation is delayed on both virgin and coated specimens. It is clearly shown that the microscopic "heat-checking" is the main factor determining the premature cracking of the steel and that the crack propagation mechanisms are assisted by oxidation at high temperature.

\section{References}

[1] Kaufman JG, Rooy EL. Aluminum alloy castings: properties, processes, and applications. ASM International, Materials Park, OH (USA): American Foundry Society; 2004.

[2] Manson SS. Thermal fatigue of die casting dies - A Review and Proposed Future Program. Tech rep. 01-72-05D. DCRF Technical Committee; 1972.

[3] Sjostrom J, Bergström J. Thermal fatigue in hot-working tools. Scand J Metall 2005;34(4):221-31.

[4] Graham RR, Wallace JF. Thermal Processing Structure and Thermal Fatigue Relation for Die Steel. DCRF Technical Bulletin 01-74-05D, CWRU; 1974.

[5] Norström L, Klarenfjord B, Svensson M. General aspects on "washout" mechanisms in aluminium die casting dies. In: Transactions of the 17th International Die Casting Congress, Cleveland (USA); 1993. p. 219-25.

[6] Chen ZW, Jahedi MZ. Die erosion and its effect on soldering formation in high pressure die casting of aluminium alloys. Mater Des 1999;20(6):303-9.

[7] Shankar S, Apeli D. Die soldering - A metallurgical analysis of the molten aluminium/die interface reactions. In: Transactions of the North American Die Casting Association (NADCA) Congress and Exposition; 1997. p. 243-51.

[8] Gopal S, Lakare A, Shivpuri R. Soldering in die casting: aluminum alloy and die Steel interactions. Die Cast Eng 2000;44(3):70-81.

[9] Etude Salem M. de l'endommagement par fatigue thermique des moules de fonderie sous pression d'aluminium: effet de l'interaction avec l'aluminisation et l'oxydation $\mathrm{PhD}$ thesis Université de Paul Sabatier Toulouse; 2009

[10] Chacrone A, Baltzinger C, Bessières A, Heizmann J. Kinetic and metallographic study of the formation of the alloy layer during the coating of steel with an aluminium-silicon mixture. Mémoires et Etudes Scientifiques de la Revue de Métallurgie, Revue de Metallurgie 1987;84(9):435.

[11] Mitterer C, Holler F, Üstel F, Heim D. Application of hard coatings in aluminium die casting - soldering, erosion and thermal fatigue behaviour. Surf Coat Technol 2000;125(1-3):233-9.

[12] Kosec BK, Kosec L, Kopač J. Analysis of casting die failures. Eng Fail Anal 2001;8(4):355-9.

[13] Sundqvist M, Hogmark S. Effects of liquid aluminium on hot-work tool steel. Tribol Int 1993;26:129-34.

[14] Joshi V, Srivastava A, Shivpuri R. Intermetallic formation and its relation to interface mass loss and tribology in die casting dies. Wear 2004;256(11-12):1232-5.

[15] Zhu Y, Schwam D, Wallace JF, Birceanu S. Evaluation of soldering, washout and thermal fatigue resistance of advanced metal materials for aluminum die-casting dies. Mater Sci Eng A 2004;379(1-2):420-31.

[16] Chen ZW. Formation and progression of die soldering during high pressure die 
casting. Mater Sci Eng A 2005;397:356-69.

[17] Persson A, Hogmark S, Bergström J. Thermal fatigue cracking of surface engineered hot work tool steels. Surf Coat Technol 2005;191(2):216-27.

[18] Miquel B, Jean S, Le Roux S, Lamesle P, Rézaï-Aria F. Heat-checking of hot work tool steels. Eur Struct Integr Soc 2002;29:185-93.

[19] Medjedoub F, Le Roux S, Dour G, Rézaï-Aria F. Effect of local stress on the heatchecking morphology in high temperature tool steels under thermal fatigue: Transition from multi-axiality to uniaxiality. Mech Mater 2014;69(1):159-72.

[20] Danzer R, Sturm F, Schindler A, Zleppnig W. Thermal fatigue cracks in pressure die casting dies. Gisserei-Praxis 1983;19(20):287-97.

[21] Berns H. Beispiele zur schädigung von warmarbeitswerkzeugen. J Heat Treat Mater 2004:59(6):379-87.

[22] Tsujii N, Abe G, Fukura K, Sunada H. Effect of testing atmosphere on low cycle fatigue of hot work tool steel at elevated temperature. ISIJ Int 1995;35:920-6.

[23] Howes MAH. A Study of Thermal Fatigue Mechanisms. In: Proc. Thermal Fatigue of Materials and Components, American Society for Testing and Materials; 1976. p. 87-105.

[24] Malm S, Norström LÅ. Material-related model for thermal fatigue applied to tool steels in hot-work applications. Metal Sci 1979;13(9):544-50.

[25] Wallace JF, Wang Y, Schwam S. Effect of composition and processing on the thermal fatigue and toughness of high performance die steel. Die Cast Eng 1997;41(5):26.

[26] Ebner R, Marsoner S, Siller I, Ecker W. Thermal fatigue behaviour of hot-work tool steels: heat check nucleation and growth. Int J Microstruct Mater Prop 2008;3(2-3):182-94.

[27] Medjedoub F, Dour G, Le Roux S, Lamesle P, Salem M, Hairy P, et al. Experimental conditions and environment effects on thermal fatigue damage accumulation and life of die-casting steel X38CrMoV5 (AISI H11). Int J Microstruct Mater Prop 2008;3(2-3):336-49.

[28] Klobčar D, Tušek J, Taljat B. Thermal fatigue of materials for die-casting tooling. Mater Sci Eng A 2008;472:198-207.

[29] Nicholls JH. The production and properties of aluminium coatings. Product Finish 1962;15(10):61-8.

[30] Drewett R. Diffusion coatings for the protection of iron and steel: Part 1: Aluminium coatings. Anti-Corrosion Methods Mater 1969;16(4):11-6.

[31] Majumdar S, Paul B, Kain V, Dey GK. Formation of $\mathrm{Al}_{2} \mathrm{O}_{3} / \mathrm{Fe}-\mathrm{Al}$ layers on SS 316 surface by pack aluminizing and heat treatment. Mater Chem Phys 2017;190:31-7.

[32] Medvedeva A, Bergström J, Gunnarsson S, Andersson J. High-temperature properties and microstructural stability of hot-work tool steels. Mater Sci Eng A 2009;523(1):39-46.

[33] Mevrel R, Duret C, Pichoir R. Pack cementation processes. Mater Sci Technol 1986;2(3):201-6.

[34] Xiang ZD, Datta PK. Relationship between pack chemistry and aluminide coating formation for low-temperature aluminisation of alloy steels. Acta Mater 2006;54(17):4453-63.

[35] Rohr V. Development of novel protective high temperature coatings on heat exchanger steels and their corrosion resistance in simulated coal firing environment $\mathrm{PhD}$ thesis INP Toulouse2005.

[36] Qayyum F, Shah M, Shakeel O, Mukhtar F, Salem M, Rézai-Aria F. Numerical simulation of thermal fatigue behavior in a cracked disc of AISI H-11 tool steel. Eng Fail Anal 2016;62:242-53.

[37] Salem M, Velay V, Cheikh C, Dour G, Lamesle P, Rezai-Aria F. Fatigue life modelling of hot forming tools. In: Proc of 8th International Tooling Conference, 2009. p. 455-64.

[38] Schütze M. Protective oxide scales and their breakdown. New York: J. Wiley \& Sons; 1997.
[39] Spera DA. What is thermal fatigue? Thermal fatigue of materials and components. ASTM STP 1976;612:3-9.

[40] Le Roux S, Medjedoub F, Dour G, Rézaï-Aria F. Role of heat-flux density and mechanical loading on the microscopic heat-checking of high temperature tool steels under thermal fatigue experiments. Int J Fatigue 2013;51:15-25.

[41] Velay V, Bernhart G, Penazzi L. Cyclic behavior modeling of a tempered martensitic hot work tool steel. Int J Plasticity 2006;22(3):459-96.

[42] Grüning A, Lebsanft M, Scholtes B. Cyclic stress-strain behavior and damage of tool steel AISI H11 under isothermal and thermal fatigue conditions. Mater Sci Eng A 2010;527(7-8):1979-85.

[43] Schütze M. Deformation and cracking behavior of protective oxide scales on heatresistant steels under tensile strain. Oxid Met 1985;24(3-4):199-232.

[44] Nagl MM, Evans WT. The mechanical failure of oxide scales under tensile or compressive load. J Mater Sci 1993;28(23):6247-60.

[45] Strawbridge A, Evans HE. Mechanical failure of thin brittle coatings. Eng Fail Anal 1995;2(2):85-103.

[46] Teixeira V. Residual stress and cracking in thin PVD coatings. Vacuum 2002;64(3-4):393-9.

[47] Schütze M, Tortorelli PF, Wright IG. Development of a comprehensive oxide scale failure diagram. Oxid Met 2010;73:389-418.

[48] Potesser M, Schoeberl T, Antrekowitsch H, Bruckner J. The characterization of the intermetallic Fe-Al layer of steel-aluminum weldings. In: EPD Congress, Curran Associates Incorporated, New York (USA); 2006. p. 167-76.

[49] Deqing W. Phase evolution of an aluminized steel by oxidation treatment. Appl Surf Sci 2008;254(10):3026-32.

[50] Novák P, Michalcová A, Marek I, Mudrová M, Saksl K, Bednarčík J, et al. On the formation of intermetallics in Fe-Al system-An in situ XRD study. Intermetallics 2013;32:127-36.

[51] Zamanzade M, Barnoush A, Motz C. A review on the properties of iron aluminide intermetallics. Crystals 2016;6(1):10.

[52] Chen ZW, Jahedi MZ. The effect of temperature on soldering and the sequence of formation of the soldered layer during high pressure die casting of $\mathrm{Al}-11 \mathrm{Si}-3 \mathrm{Cu}$ alloy. Int J Cast Metal Res 1998;11(3):129-38.

[53] Chen ZW, Fraser DT, Jahedi MZ. Structures of intermetallic phases formed during immersion of $\mathrm{H} 13$ tool steel in an Al-11Si-3Cu die casting alloy melt. Mater Sci Eng A 1999;260(1-2):188-96.

[54] Persson A, Hogmark S, Bergstrom J. Failure modes in field-tested brass die casting dies. J Mater Process Technol 2004;148:108-18.

[55] Srivastava A, Joshi V, Shivpuri R. Computer modeling and prediction of thermal fatigue cracking in die-casting tooling. Wear 2004;256:38-43.

[56] Muhič M, Tušek J, Kosel F, Klobčar D, Pleterski M. Thermal fatigue cracking of diecasting dies. Metalurgija 2010;49(1):9-12.

[57] Navinšek B, Panjan P, Milošev I. Industrial applications of CrN (PVD) coatings, deposited at high and low temperatures. Surf Coat Technol 1997:97(1):182-91.

[58] Starling CMD, Branco JRT. Thermal fatigue of hot work tool steel with hard coatings. Thin Solid Films 1997;30(8):436-42.

[59] Wang Y. A study of PVD coatings and die materials for extended die-casting die life. Surf Coat Technol 1997;94:60-3.

[60] Gulizia S, Jahedi MZ, Doyle ED. Performance evaluation of PVD coatings for high pressure die casting. Surf Coat Technol 2001;140(3):200-5.

[61] Srivastava A, Joshi V, Shivpuri R, Bhattacharya R, Dixit S. A multilayer coating architecture to reduce heat checking of die surfaces. Surf Coat Technol 2003;163:631-6.

[62] Peter I, Rosso M, Gobber FS. Study of protective coatings for aluminum die casting molds. Appl Surf Sci 2015;358:563-71. 